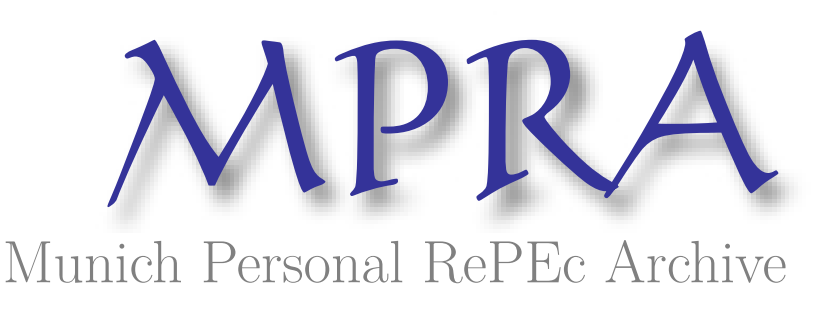

\title{
Optimal Collusion under Cost Asymmetry
}

Miklos-Thal, Jeanine

2008

Online at https://mpra.ub.uni-muenchen.de/11044/

MPRA Paper No. 11044, posted 12 Oct 2008 11:07 UTC 


\title{
Optimal Collusion under Cost Asymmetry
}

\author{
Jeanine Miklós-Thal*
}

June 2008

\begin{abstract}
Cost asymmetry is generally thought to hinder collusion because a more efficient firm has both more to gain from a deviation and less to fear from retaliation than less efficient firms. Our paper reexamines this conventional wisdom and characterizes optimal collusion without any prior restriction on the class of strategies. We first stress that firms can credibly agree on retaliation schemes that maximally punish even the most efficient firm. This implies that whenever collusion is sustainable under cost symmetry, some collusion is also sustainable under cost asymmetry; efficient collusion, however, remains more difficult to sustain when costs are asymmetric. Finally, we show that, in the presence of side payments, cost asymmetry generally facilitates collusion.
\end{abstract}

keywords: horizontal collusion, cost asymmetry, optimal punishments, side payments

JEL codes: L11, L41, C72

${ }^{*}$ University of Mannheim, Fakultät für Volkswirtschaftslehre, L7,9, 68131 Mannheim, Germany - jeaninethal@gmail.com. This paper is based on chapter 2 of my doctoral dissertation at the University of Toulouse 1, written under the supervision of Patrick Rey. The paper has also benefitted from comments by the editor Dan Kovenock, two anonymous referees, Mohamed Belhaj, Bruno Jullien, Ulrich Kamecke, Joe Harrington and participants of the 2004 WZB/CEPR "Collusion and Cartels" conference, the Econometric Society World Congress 2005, and the European Winter Meeting of the Econometric Society 2005. Any remaining errors are my own. 


\section{Introduction}

Economists and policy-makers generally agree that cost asymmetry hinders collusion. In his classical industrial organization textbook for example, Scherer (1980) states that "...the more cost functions differ from firm to firm, the more trouble firms will have maintaining a common price policy". The US Merger Guidelines refer to some of the underlying arguments for this conventional wisdom when stating that "...the extent of homogeneity may be relevant both for the ability to reach terms of coordination and to detect or punish deviations from those terms".

There are three main reasons why cost asymmetry is thought to hinder collusion. ${ }^{1}$ First, coordination problems are obviously more complex when firms have divergent preferences concerning collusive prices and there are no natural focal points. Second, it may be difficult to convince an efficient firm to join a cartel, since it may earn relatively high profits even under competition. Third, cost asymmetry may also hinder the sustainability of collusion, since (i) it may be more difficult to retaliate against an efficient firm in case it deviates from the cartel agreement, and (ii) a more efficient firm may gain relatively more from deviating in the short-term.

This paper examines the sustainability of collusion in homogenous-good Bertrand oligopoly supergames with discounting where firms face different unit costs. Our aim is to analyze the maximum scope for collusion. Threats of severe retaliation against cheating firms are clearly optimal for cartel stability, since they reduce deviation incentives and thereby facilitate cooperation. Of course, punishment threats must be credible to be effective. We illustrate that there exist credible punishments that leave any cheating firm with zero continuation profits. Hence, even if the deviator faces lower marginal production costs than all other industry participants, the other firms can credibly force the deviator down to minmax continuation profits. Thus, cost asymmetry weakens retaliation only if there is some reason why firms should use standard trigger strategies or other restricted forms of punishments instead of these maximal credible punishments.

This implies that a more efficient firm does not necessarily have stronger incentives to deviate from a collusive agreement than a less efficient firm. Suppose, for instance, that the industry is made up of two firms, and that the more efficient firm has a non-drastic cost advantage over the less efficient firm. Consider a stationary collusive path on which the price is equal to the low-cost firm's monopoly price and firms split demand equally in

\footnotetext{
${ }^{1}$ See Ivaldi et al. (2003) for an overview of the different arguments.
} 
every period. The optimal one-shot deviation for each firm is then to slightly undercut the collusive price so as to "steal" its rival's consumers, thereby doubling its profit in the deviation period. The firms' relative short-term deviation incentives are hence symmetric. Therefore, when all punishments indeed minmax deviators, so that deviators' punishment profits are symmetric as well, the critical discount factor for this collusive scheme is $\frac{1}{2}$. The discount factor threshold for some collusion is thus the same under cost asymmetry as under cost symmetry.

This conclusion differs from those in the previous literature that has focused on grim trigger strategies. Bae (1987) as well as Harrington (1991), whose frameworks very closely resemble ours, determine the set of prices and output quotas sustainable by standard grim trigger strategies. Since the most efficient firm's punishment profit increases with the size of its cost advantage in this case, cost asymmetry renders the deterrence of deviations more difficult. Cost asymmetry therefore hinders collusion sustained by standard grim trigger strategies, even if allowing for inefficient allocations from the viewpoint of the cartel so as to render short-term deviation gains symmetric.

When the focus is on collusive allocations that are Pareto-efficient for the cartel members (in the absence of side payments), on the other hand, our qualitative results are in line with the previous literature. Unless only the most efficient firm produces, Paretoefficiency for the firms requires a price above the most efficient firm's monopoly price. For such prices, however, the most efficient firm has a disproportionately high deviation gain: it not only gains market share, but also switches to its profit-maximizing price. Firms with higher monopoly prices have relatively less to gain from a deviation. Collusion on a statically Pareto-efficient allocation is thus more difficult to sustain under cost asymmetry than under cost symmetry.

This paper focuses on the sustainability of collusion rather than on how firms select a specific equilibrium and coordinate on it. As is well known, repeated games generally have a multitude of equilibria and there is no uncontested method to select one of them. Firms may even be "locked" into a bad equilibrium in which some cartel members earn less than in the absence of any collusion. Nonetheless, our analysis gives some guidance as to which collusive equilibria firms may reasonably select, since we characterize the Pareto frontier of the set of payoffs attainable on stationary perfect equilibrium paths. ${ }^{2}$

\footnotetext{
${ }^{2}$ Schmalensee (1987) applies a variety of selection criteria to model the choice of price and output quotas by an asymmetric cartel. His paper, however, does not examine explicitly whether a selected outcome is also sustainable. Bae (1987) and Harrington (1991), on the other hand, analyze the selection
} 
Another contribution of our paper is to analyze the role of side transfers. As Bain (1948) argued more than 50 years ago, if firms have different marginal costs, the maximization of industry profits by a cartel requires side payments: without transfers, some production must be allocated to high-cost firms to induce their compliance. While antitrust rules typically prohibit direct transfers, there is evidence that some (illegal) cartels nevertheless use illegal payments. In the Florida bid rigging scheme for providing school milk, for example, dairies used side payments to compensate cartel members for refraining from bidding. ${ }^{3}$ In the worldwide lysine cartel, firms with realized market shares above their allotments had to compensate the other firms through inter-firm sales. ${ }^{4}$ In the New York trash haulers cartel, "[an] undercover police detective posing as a carting executive paid more than $\$ 790,000$ in "dues" to the [trash haulers'] associations and in compensation to other carters". 5

Our analysis confirms that side payments facilitate collusion between asymmetric firms; more surprisingly, it also shows that cost asymmetry generally facilitates collusion when side payments are feasible. The latter result runs completely counter to the conventional wisdom on the impact of cost asymmetries. Side transfers allow firms to increase the total pie by allocating more production to the most efficient firm without inducing a deviation by a less efficient firm. In a way, firms agree on a mutually beneficial scheme of compensation payments for being inactive.

While side transfers are typically ruled out in complete-information models of collusion like ours, they play an important role in the existing literature on (explicit as well as implicit) cartels between privately informed firms. The difficulty there is to induce firms to truthfully report their potentially asymmetric costs so as to allocate production efficiently. In this context, side transfers - from the firm with the lowest reported cost to the other cartel members - can be used as part of a mechanism to ensure truthtelling. However, the early literature analyzing this idea (Roberts (1985), Cramton and Palfrey (1990), Kihlstrom and Vives (1992) and McAfee and McMillan (1992)) does not model dynamics

of an allocation within the set of collusive outcomes sustainable by standard grim trigger strategies; Bae uses the balanced temptation requirement of Friedman (1971), while Harrington (1991) applies the more general Nash bargaining solution. Our analysis of the Pareto frontier of sustainable allocations corresponds to the set of Nash bargaining solutions with minmax profits as threat points.

${ }^{3}$ See Pesendorfer (2000).

${ }^{4}$ See Hammond (2005). Similar compensation schemes were also employed in the citric acid cartel (see European Commission (2001)), or the sodium gluconate cartel (see European Commission (2002)).

${ }^{5}$ See Porter (2005) for this citation from the New York Times, June 23, 1995. 
explicitly. More recently, Athey and Bagwell (2001, 2006) consider Bertrand supergames in which firms receive privately observed cost shocks in every period. When firms cannot make side transfers, future market share favors can then be used as a means of providing thruthtelling incentives to firms with high cost realizations. As also shown by Athey and Bagwell (2001), side transfers further help collusion by facilitating information revelation and thus the efficient allocation of production.

On the theoretical side, our paper also relates to the literature on collusion under other forms of competition or cost asymmetry. In the existing literature on collusion in asymmetric Cournot supergames, the authors often either choose to or are bound to impose some restrictions on the strategies considered. Rothschild (1999) uses standard grim trigger strategies, which again implies that more efficient firms have less to fear from retaliation than less efficient cartel members. Vasconcelos (2005) looks for more general punishments in the class of equilibria with proportional market shares on all equilibrium paths; he shows that optimal punishments, with a stick-and-carrot structure as proposed by $\operatorname{Abreu}(1986,1988)$, exist within this restricted class of equilibria. For a limited range of parameters, these punishments are also maximal and would thus be optimal even without any restrictions.

In the related literature on collusion with asymmetric capacity constraints where firms compete in prices, the characterization of optimal punishments is unfortunately quite difficult. While Lambson (1987) shows that optimal punishments exist in models with symmetric capacity constraints, Lambson (1994) provides only a partial characterization in the asymmetric case. The impact of asymmetry in capacities on collusive sustainability was studied by Davidson and Deneckere (1990) in the context of standard grim trigger strategies. Compte, Jenny and Rey (2002) extend this analysis and allow for harsher punishments, but restrict attention to a particular class of equilibria where market shares along any punishment path are the same as on the collusive path and the firms' prices are symmetric on any equilibrium path. Dechenaux and Kovenock (2003) extend this literature by allowing each (capacity constrained) firm to set in every period not only its price but also the maximum quantity the firm is willing to sell at that price. In the thus altered game, the authors construct credible stick-and-carrot punishments that improve upon, in the sense of being more severe, the punishments applied in Lambson (1994) as well as in Compte, Jenny and Rey (2002). Finally, Lambson (1995) allows for small asymmetries in marginal costs as well as in capacity constraints and discount rates. In this very general framework, he shows that if the game is nearly symmetric, then optimal 
punishments minmax deviators.

Our analysis proceeds as follows. Section 2 sets out the framework. Section 3 discusses optimal punishments in models of repeated price setting when firms have asymmetric unit costs. Section 4 deals with stationary collusion without side payments. We first derive the set of all sustainable collusive outcomes as a function of the discount factor. Next, we restrict attention to Pareto-efficient collusion. We also derive the Pareto frontier of sustainable allocations, i.e. the Pareto-efficient subset of the set of all sustainable allocations. In section 5, which has the same structure as section 4, we allow for side payments. Section 6 concludes. All proofs are relegated to the appendix.

\section{Framework}

We consider a simple model of infinitely repeated Bertrand competition between $n \geq 2$ firms indexed by $i=1,2, \ldots, n$. Entry by other firms is blockaded; it may, however, happen that not all $n$ firms indeed sell in equilibrium. ${ }^{6}$ Firms produce perfect substitutes, but may face different constant marginal costs of production:

$$
0<c_{1} \leq c_{2} \leq \ldots \leq c_{n}
$$

Aggregate demand for the firms' output as a function of the price $p$ is $D(p): \mathbb{R}_{+} \rightarrow \mathbb{R}_{+}$. We make the following assumptions:

A1 There exists a finite choke price $\bar{p}>c_{n}$ such that $D(p)>0$ if $p<\bar{p}$, and $D(p)=0$ if $p \geq \bar{p}$.

A2 $D(p)$ is continuous and strictly decreasing on $[0, \bar{p}]$, and twice continuously differentiable on $(0, \bar{p})$.

A3 For all $i \in\{1, \ldots, n\}, \pi_{i}(p) \equiv\left(p-c_{i}\right) D(p)$ is strictly concave on $\left[c_{i}, \bar{p}\right]$.

For every firm $i \in\{1, \ldots, n\}$, there then exists a unique monopoly price $p_{i}^{m} \in\left(c_{i}, \bar{p}\right)$ that maximizes $\pi_{i}(p)$. A standard argument ensures that $p_{1}^{m} \leq p_{2}^{m} \leq \ldots \leq p_{n}^{m}$. Unless explicitly stated otherwise, we assume that the cost advantage of firm 1 compared to firm 2 is non-drastic:

$$
p_{1}^{m}>c_{2}
$$

\footnotetext{
${ }^{6}$ The source of advantage of each of the $n$ firms - whether it is actively selling or not - over outsiders could for example be a patent or a licence that cannot be traded freely.
} 
In this set-up, we analyze the subgame perfect equilibria of the supergame obtained by infinitely repeating the stage game described next and discounting payoffs with discount factor $\delta \in(0,1)$.

In the stage game, firms simultaneously choose prices. We assume that no firm ever sets a price outside of $[0, \bar{p}]$, and denote the vector of prices in period $t=0,1,2, \ldots$ by $P^{t}=\left(p_{1}^{t}, p_{2}^{t}, . ., p_{n}^{t}\right) \in[0, \bar{p}]^{n}$. In every period, the whole market demand goes to the lowest priced firm(s). In case of a price tie at the lowest price, consumers are indifferent between a number of sellers, and we will allow total demand to be split between the lowest priced firms in any way consistent with the equilibrium (that is, no firm has an incentive to deviate to a different price). ${ }^{7}$ We denote by $\Delta^{n-1}$ the $(n-1)$-dimensional unit simplex: $\Delta^{n-1}=\left\{\left(s_{1}, s_{2}, \ldots, s_{n}\right) \in \mathbb{R}^{n} \mid s_{i} \geq 0\right.$ for all $\left.i, \sum_{i=1}^{n} s_{i}=1\right\}$. The market sharing rule in period $t$ is then a mapping $s^{t}(\cdot): \mathbb{R}_{+}^{n} \rightarrow \Delta^{n-1}$ such that $s_{i}^{t}(\cdot)=0$ if $p_{i}^{t} \neq \min _{j \in\{1, n\}}\left\{p_{j}^{t}\right\}$.

In the infinite horizon game obtained by repeating this price game, a path is an infinite sequence of actions $\left\{P^{t}\right\}_{t=0}^{\infty}$. Given the sequence of market sharing rules $\left\{s^{t}(\cdot)\right\}_{t=0}^{\infty}$, firm $i$ 's sum of discounted payoffs from period $s$ onwards along the path $\left\{P^{t}\right\}_{t=0}^{\infty}$ is $\sum_{t=s}^{\infty} \delta^{t-s} s_{i}^{t}\left(P^{t}\right) \pi_{i}\left(p_{i}^{t}\right)$. A firm's strategy ${ }^{8}$ is an infinite sequence of action functions, where the period $t$ action function maps from the set of possible histories of the game at time $t$, $[0, \bar{p}]^{n t}$, into $[0, \bar{p}]$.

\section{Minmax Punishments}

For tacit collusion to be successful, firms need to agree on some credible retaliation mechanism to punish deviations. The scope for collusion is greatest if deviations from the collusive agreement are punished as harshly as possible. By the same logic, it is easiest to punish a firm if deviations from the prescribed punishment are retaliated against as severely as possible.

The minmax of each firm's profit is zero in our model: while a firm can always avoid negative profits by charging a price above its marginal cost, any other firm can drive its profits down to zero by undercutting its price. A security level punishment for firm $i$ is

\footnotetext{
${ }^{7}$ In his closely related analysis, Harrington (1991) also assumed that demand is divided between the lowest priced firms in any way consistent with the equilibrium. Bernheim and Whinston (1990, p. 4, footnote 8) point out that a useful way to think about this is to imagine that products are almost perfectly homogenous. For a sufficiently small degree of product differentiation, prices can then be set at slightly different levels so as to achieve any desired split of market demand with almost no effect on profits.

${ }^{8}$ We restrict attention to pure strategies.
} 
thus a path with a continuation value of zero for firm $i$. Obviously, if firms are able to credibly "collude" on punishment strategies such that any deviation by a particular firm triggers a security level punishment for this firm (that is, if such punishment strategies can arise as part of a perfect equilibrium of the supergame), then these punishment strategies maximize the scope for collusion, and the optimal penal code is a security level penal code. $^{9}$

We will now argue that there indeed exists a security level penal code for any $\delta \in(0,1)$ in the game considered here. The focus will be on trigger strategy profiles generating punishment paths that consist of a constant sequence of some static Bertrand-Nash equilibrium (where the selection of the static equilibrium may depend on the identity of the deviator).

If $c_{1}=c_{2} \leq \ldots \leq c_{n}$, it is easy to punish any deviator down to minmax continuation profits by means of standard Nash reversion: firms can simply agree to revert upon any deviation to the one-shot Bertrand equilibrium in which each firm $i$ sets price $c_{i}$, and all firms earn zero profits. ${ }^{10}$

If $c_{1}<c_{2} \leq \ldots \leq c_{n}$, then there is a continuum of Bertrand equilibria in the underlying stage game. Consider any price $p_{1} \in\left[c_{1}, c_{2}\right]$. With any market sharing rule that assigns all the demand to firm 1 if it is one of the lowest priced firms (at price $p_{1}$ ), the following is a one-shot Bertrand equilibrium: firm 1 posts price $p_{1}$, firm 2 posts price $p_{1}$, and any firm $i \in\{3, \ldots, n\}$ posts price $c_{i} \cdot{ }^{11}$ Firm 1's equilibrium profit is $\pi_{1}\left(p_{1}\right) \in\left[0, \pi_{1}\left(c_{2}\right)\right]$. There hence always exists a static equilibrium in which firm 1 earns minmax profits.

Now consider the following trigger punishments:

- any deviation by firm 1 triggers reversion to the one-shot Bertrand equilibrium described above in which consumers pay $c_{1}$; formally, in every period from the first period after the deviation onwards the price vector is $\left(c_{1}, c_{1}, c_{3}, \ldots, c_{n}\right)$ and the vector of market shares is $(1,0, \ldots, 0)$.

\footnotetext{
${ }^{9}$ We focus on punishment strategy profiles such that any deviation by a particular firm, be it from collusion or from a punishment already in play, triggers the start of the same (firm-specific) punishment path. Abreu (1988) shows that this focus on simple penal codes does not imply any loss of generality. If several firms deviate simultaneously, no punishment is started.

${ }^{10}$ Any market sharing rule is consistent with this static equilibrium.

${ }^{11}$ Note also that if we allow for mixed strategies, then any price between $c_{1}$ and $c_{2}$ can be supported in equilibrium without making appeal to a market sharing rule favoring firm 1 . In such equilibria, firm 2 randomizes in a neighbourhood above the equilibrium market price $p_{1}$ while firm 1 continues to play a pure strategy. See Deneckere and Kovenock (1989 and 1996, footnote 10) and Blume (2003).
} 
- any deviation by a firm $i \neq 1$ triggers reversion to the one-shot Bertrand equilibrium decribed above in which consumers pay $c_{2}$; formally, in every period from the first period after the deviation onwards the price vector is $\left(c_{2}, c_{2}, c_{3}, \ldots, c_{n}\right)$ and the vector of market shares is $(1,0, \ldots, 0)$.

Clearly, these are security level punishments. Moreover, it is trivial that no firm has an incentive to deviate from any of these punishments: no firm can make a short-term gain by deviating from a static equilibrium, but a deviation starts a security level punishment for the deviator.

Even if $c_{1}<c_{2}$, an optimal penal code thus prescribes security level punishments for all firms, including firm 1 . This means that the conventional wisdom that retaliation against an efficient firm is difficult hinges upon the use of non-optimal punishments. In particular, standard trigger strategies, where a deviation by any firm, including the most efficient one, triggers reversion to the one-shot equilibrium with price $c_{2}$, do not punish all firms as severely as possible.

Discussion Whenever $c_{1}<c_{2}$, then the punishment for firm 1 proposed here has a characteristic that some readers may find unattractive: in every period, firm 2 plays a weakly dominated strategy in the one-shot game. ${ }^{12}$ Indeed, in the stage game we consider it is common to rule out all the one-shot equilibria with prices strictly below $c_{2}$ as implausible, since such equilibria cannot be obtained as limits of equilibria in undominated strategies in discrete approximations to the game with a continuous strategy space. ${ }^{13}$ Two remarks are in order. First, as long as $n>2$, all that is needed for a static equilibrium that minmaxes firm 1 is for one of the other firms to charge $c_{1}$. The other $n-2$ firms can charge whatever prices they want, for instance their monopoly prices. This implies that by rotating the identity of the firm holding firm 1 down, the punishing firms can engage in a "stationary" policy that does not have any single punishing firm playing a weakly dominated strategy in the one-shot game in every period. ${ }^{14}$ Second, for $n=2$, it is easy to design an optimal penal code in which deviations by firm 1 trigger a stick-and-carrot

\footnotetext{
${ }^{12}$ Note that by setting $c_{1}$, firm 1 plays a weakly dominated strategy in the one-shot game as well; however, firm 1's strategy can be obtained as the limit of undominated strategies in discrete approximations to the game, whereas firm 2's strategy cannot. Similarly, if $c_{1}=c_{2}$, the the one-shot Bertrand equilibrium involves the play of weakly dominated strategies, but these are again limits of undominated strategies of finite strategy space games.

${ }^{13}$ See Deneckere and Kovenock (1996, footnote 8).

${ }^{14}$ I am grateful to the editor Dan Kovenock for this suggestion.
} 
punishment à la Abreu (1986, 1988), provided that the discount factor is sufficiently high for some collusion to be sustainable and thus serve as a carrot; see proposition A1 in the appendix for a proof of this in the general case with $n$ firms. Firm 2 then charges a price below $c_{2}$ only during the initial stick phase of firm 1's punishment.

\section{Collusion without Side Payments}

\subsection{Sustainability}

We define a stationary collusive outcome by a vector $(p, s)$, where $p \in\left(c_{2}, \bar{p}\right)$ is the market price, i.e. the lowest price quoted by any of the firms, and $s=\left(s_{1}, \ldots, s_{n}\right) \in \Delta^{n-1}$ is the associated vector of market shares. In this section, we characterize the set of all stationary collusive outcomes that are sustainable in a subgame perfect equilibrium. ${ }^{15}$ An outcome is sustainable if and only if it can be supported by an optimal penal code, which, as shown in the previous section, is a security level penal code in the game considered.

Note first that no sustainable stationary collusive scheme can ever assign a positive market share to a firm whose cost is above the collusive price $p$; otherwise, such a firm would make negative profits by sticking to collusion, whereas it could ensure zero continuation profits by deviating to a higher price, even if the ensuing punishment is maximal. We therefore define the set of "active firms" by ${ }^{16}$

$$
A(p)=\left\{i \mid c_{i}<p\right\}
$$

\footnotetext{
${ }^{15}$ Proposition A2 in the appendix shows that if no stationary outcome with a price strictly above $c_{2}$ can be supported in a subgame perfect equilibrium, then on any equilibrium path firm 1's nomalized discounted payoff lies in $\left[0, \pi_{1}\left(c_{2}\right)\right]$ and any firm $i \neq 1$ 's payoff is zero. As argued in section 3 , any of these payoff profiles can also be supported on a stationary path for all $\delta \in(0,1)$. If the discount factor is so low that no stationary paths with $p>c_{2}$ is sustainable, the stationarity restriction is hence without loss of generality. Therefore, the stationarity assumption does not drive the results of our comparison of the critical discount factors for some collusion under cost symmetry and under cost asymmetry. The stationarity restriction may imply a loss of generality for higher discount factors however; see the discussion concluding section 4.2.2.

${ }^{16}$ If $c_{i}=p$ and $s_{i}>0$ under collusion, firm $i$ 's non-deviation constraint would be satisfied trivially, since both its collusive and its deviation profits would be zero. Granting a positive market share to firm $i$ would then hinder collusion in the sense that some other firm's market share would need to be reduced. We therefore restrict the set of active firms to those with marginal costs strictly below the collusive price. This assumption will simplify the exposition, but does not influence the critical discount factor.
} 
Inactive firms can be thought of as potential entrants. Formally, since "exit" is not part of a firm's set of actions, we specify that each inactive firm $i$ sets $p_{i}^{m}$ in every period along the collusive path. Our focus is then on paths such that in every period $t, p_{i}^{t}=p$ if $i \in A(p)$ and $p_{i}^{t}=p_{i}^{m}$ if $i \notin A(p) .{ }^{17}$ The associated sequence of market sharing rules results in market shares $s^{t}=s \in \Delta^{n-1}$ in all time periods $t$ where obviously $s_{i}=0$ if $i \notin A(p)$.

Sustainability of collusion then boils down to the requirement that none of the active firms has an incentive to deviate from the collusive outcome. The optimal one-shot deviation $^{18}$ for a firm $i \in A(p)$ is to charge $p_{i}^{m}$ if the collusive price lies above $p_{i}^{m}$, and to slightly undercut its rivals' price otherwise. The non-deviation constraint of any active firm $i \in A(p)$ is hence

$$
\frac{1}{1-\delta} s_{i} \pi_{i}(p) \geq \pi_{i}\left(\min \left[p, p_{i}^{m}\right]\right) .
$$

A collusive outcome $(p, s)$ is sustainable if and only if it satisfies conditions $\left(C_{i}\right)$ for all $i \in A(p)$. We denote the set of all sustainable stationary collusive outcomes as a function of the discount factor by $\Lambda(\delta)$ :

$$
\Lambda(\delta) \equiv\left\{(p, s) \in\left(c_{2}, \bar{p}\right) \times \Delta^{n-1} \mid\left(C_{i}\right) \text { holds for all } i \in A(p), s_{i}=0 \text { for all } i \notin A(p)\right\}
$$

Adding up the non-deviation conditions $\left(C_{i}\right)$ of all active firms, using the fact that their market shares must add up to one, yields the following necessary condition for collusion at price $p$ :

$$
\delta \geq \widetilde{\delta}(p)
$$

where

$$
\widetilde{\delta}(p) \equiv \frac{\sum_{i \in A(p)} \frac{\pi_{i}\left(\min \left[p, p_{i}^{m}\right]\right)}{\pi_{i}(p)}-1}{\sum_{i \in A(p)} \frac{\pi_{i}\left(\min \left[p, p_{i}^{m}\right]\right)}{\pi_{i}(p)}} .
$$

It is easy to see this condition on the price is not only necessary but also sufficient: whenever (2) is satisfied, there exists a vector of market shares $s$ such that the nondeviation conditions $\left(C_{i}\right)$ hold for all active firms.

\footnotetext{
${ }^{17}$ Given stationarity, the assumption that all active firms indeed quote the market price $p$ does not restrict the analysis of sustainability. If a stationary outcome at which some firm $j \in A(p)$ sets a price $p_{j}>p$ (and thus has a market share $s_{j}=0$ ) is sustainable, then an otherwise indentical outcome with $p_{j}=p$ and $s_{j}=0$ is also sustainable: the firms' collusive profits are identical in the two scenarios, and the scope for deviations is either the same or less if firm $j$ sets $p$ instead of some higher price.

${ }^{18} \mathrm{By}$ the one-shot deviation principle, a "strategy profile is subgame perfect if and only if there are no profitable one-shot deviations" (proposition 2.2.1 in Mailath and Samuelson (2006), p. 30). It is hence sufficient to consider one-shot deviations.
} 
We denote the number of active firms, that is of elements in $A(p)$, by $m(p) \in[2, n]$. Clearly, $m(p)$ is (weakly) increasing: as the collusive price rises, more firms could profitably undercut $p$ and must therefore join the collusive agreement for it to remain sustained.

For collusive prices $p \in\left(c_{2}, p_{1}^{m}\right]$, the critical discount factor is $\widetilde{\delta}(p)=\frac{m(p)-1}{m(p)}$, which is also the threshold for collusion between $m(p)$ symmetric firms. This result arises because in this case each active firm's optimal deviation would consist in slightly undercutting its rival, and all firms' punishments impose zero continuation profits. Each active cartel member's deviation incentives then only depend on its market share relative to the discount factor, and the non-deviation constraint for any $i \in A(p)$ is simply

$$
s_{i} \geq 1-\delta
$$

Note that even for prices below the most efficient firm's monopoly price, the critical discount factor may exhibit upward jumps if the number of active firms $m(p)$ increases, so that the market must be shared by a larger number of firms to preserve collusion. Suppose for example that $n=3$, and $c_{2}<c_{3}<p_{1}^{m}$. Then the critical discount factor $\widetilde{\delta}(p)$ is $\frac{1}{2}$ for $p \in\left(c_{2}, c_{3}\right]$, but $\widetilde{\delta}(p)=\frac{2}{3}$ for $p \in\left(c_{3}, p_{1}^{m}\right]$. For $p \in\left(c_{2}, p_{1}^{m}\right], \widetilde{\delta}(p)$ is hence weakly increasing.

For $p>p_{1}^{m}$, on the other hand, the discount factor threshold $\widetilde{\delta}(p)$ is strictly increasing even if the number of active firms remains constant. This result is driven by the wedge between a firm's stand-alone collusive profits $\pi_{i}(p)$ and its deviation profits $\pi_{i}\left(p_{i}^{m}\right)$ whenever $p>p_{i}^{m}$. Given any market sharing rule, firm $i$ 's incentive to deviate is then clearly higher the larger the (positive) difference between the collusive price and its own monopoly price. For $p>p_{1}^{m}$, this difference is positive for at least the most efficient firm 1 , which drives up the critical discount factor. If the collusive price exceeds the monopoly prices of several firms, this effect is further reinforced.

The critical discount factor is thus increasing in $p$ for two reasons: (i) a price increase may attract "entry", which in turn forces firms to share the market with more firms in order to preserve collusion, and (ii) by creating or increasing the wedge between standalone collusive profits and short-term deviation profits, higher prices may increase the deviation incentives of already active firms. Note that $\lim _{p \rightarrow \bar{p}} \widetilde{\delta}(p)=1$.

The minimum market share that must be granted to an active firm $i \in A(p)$ such that collusion at price $p \in\left(c_{2}, \bar{p}\right)$ is indeed sustainable for some discount factor $\delta \geq \widetilde{\delta}(p)$ is

$$
\widetilde{s}_{i}(p, \delta) \equiv(1-\delta) \frac{\pi_{i}\left(\min \left[p, p_{i}^{m}\right]\right)}{\pi_{i}(p)} .
$$


This lower bound $\widetilde{s}_{i}(p, \delta)$ is such that $\left(C_{i}\right)$ is binding. Moreover, each firm's market share is restricted upwards by the other firms' non-deviation constraints. In particular, the maximum market share that can possibly be granted to firm $i$ without triggering a deviation by some other firm is $1-\sum_{j \in A(p) \backslash i} \widetilde{s}_{j}(p, \delta)$. For $p \in\left(c_{2}, p_{1}^{m}\right]$, when the nondeviation constraints are independent of the collusive price, market shares are restricted by $s_{i \in A(p)} \in[1-\delta, 1-(m(p)-1)(1-\delta)]$ and $\sum_{i \in A(p)} s_{i}=1$, as under cost symmetry between $m(p)$ firms. For prices above $p_{i}^{m}$, the lower bound on firm $i$ 's market share, $\widetilde{s}_{i}(p, \delta)$, strictly increases with the price to accommodate $i$ 's increasing deviation incentives.

The set of all sustainable allocations as a function of the discount factor can then be expressed as follows:

$$
\Lambda(\delta)=\left\{\begin{array}{c}
(p, s) \in\left(c_{2}, \bar{p}\right) \times \Delta^{n-1} \mid \widetilde{\delta}(p) \leq \delta, s_{i}=0 \text { for all } i \notin A(p), \\
s_{i} \in\left[\widetilde{s}_{i}(p, \delta), 1-\sum_{j \in A(p) \backslash i} \widetilde{s}_{j}(p, \delta)\right] \text { for all } i \in A(p)
\end{array}\right\}
$$

The impact of the discount factor on the size of the set $\Lambda(\delta)$ is as follows. First, since $\frac{\partial \widetilde{\delta}(p)}{\partial p} \geq 0$ as explained above, the set of prices satisfying $\widetilde{\delta}(p) \leq \delta$ (weakly) increases with $\delta$. Second, $\frac{\partial \widetilde{s}_{i}(p, \delta)}{\partial \delta}<0$, which implies for any given sustainable price the set of possible collusive market shares expands as the discount factor rises.

Figure 1 provides a graphical representation of $\Lambda(\delta)$ when $n=2$. In this case, $\left(p, s_{1}\right)$ fully defines an outcome, with the understanding that $s_{2}=1-s_{1}$. For $\delta$ below $\frac{1}{2}$, the discount factor threshold under cost symmetry, no collusion is sustainable: $\Lambda(\delta)=\varnothing$ if $\delta<\frac{1}{2}$. For $\delta=\frac{1}{2}$, the set of sustainable outcomes consists of all allocations such that $p \in\left(c_{2}, p_{1}^{m}\right]$ and $s_{1}=\frac{1}{2}$. As under cost symmetry, only equal market sharing rules are sustainable at the critical discount factor $\frac{1}{2}$. For higher discount factors, prices above $p_{1}^{m}$ and asymmetric market sharing rules are sustainable as well. This is illustrated in Figure 1 for some $\delta^{\prime} \in\left(\frac{1}{2}, \widetilde{\delta}\left(p_{2}^{m}\right)\right]$. The set of sustainable allocations $\Lambda\left(\delta^{\prime}\right)$ includes all outcomes in the striped region, that is, all allocations that are (i) left of or on the line labelled $C_{2}\left(\delta^{\prime}\right)$, along which firm 2 is indifferent between complying and deviating, and (ii) right of or on the line labelled $C_{1}\left(\delta^{\prime}\right)$, along which firm 1 is indifferent between deviating and complying. Both non-deviation constraints are binding at the maximal collusive price, which is denoted by $p^{\prime}$ in the figure. Note that since $\widetilde{\delta}(p)$ is strictly increasing for $p>p_{1}^{m}$, the highest sustainable price $p^{\prime}$ is uniquely defined by the condition $\widetilde{\delta}\left(p^{\prime}\right)=\delta^{\prime}$. 


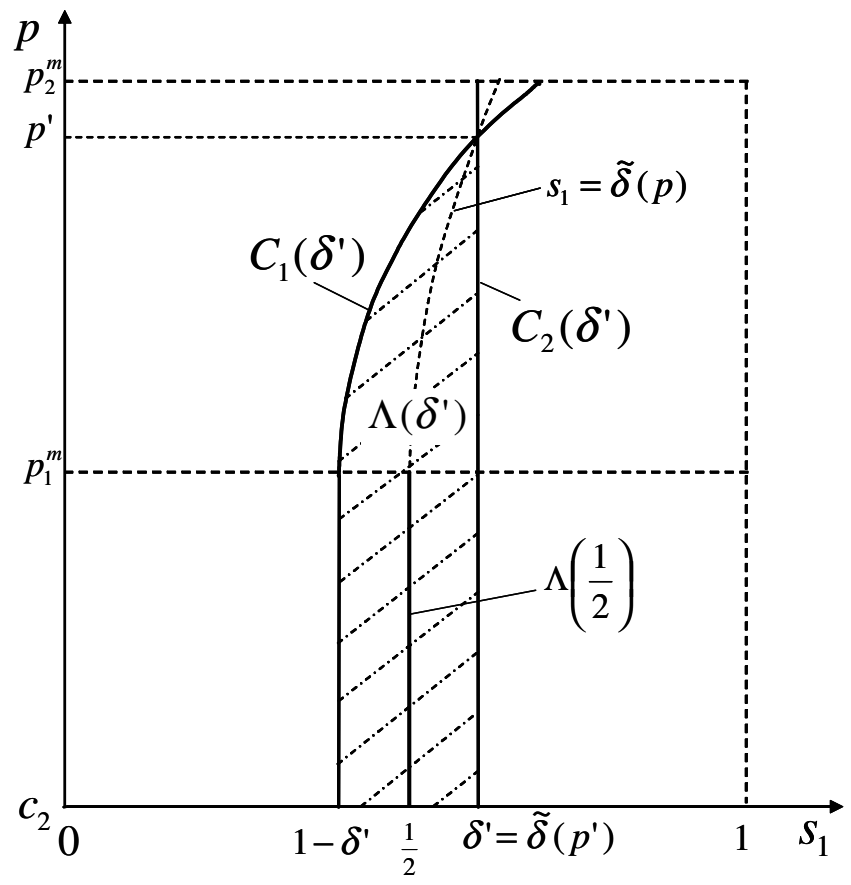

Figure 1: Sustainable Collusive Outcomes without Side Payments $(n=2)$

\subsection{Pareto-Efficient Collusion}

The previous section provided a complete characterization of the set of sustainable stationary collusive outcomes. It is clear, however, that an outcome that is sustainable may fail to be optimal in the sense that the firms could achieve a Pareto-improvement by moving to another sustainable outcome.

In this section, we incorporate the concern of Pareto-efficiency (for the firms) into the analysis. For simplicity, we restrict attention to an industry with only two firms, i.e. $n=2$, for the whole section. The analysis will consist of two main parts. First, we derive the set of allocations that are Pareto-efficient for the firms in the stage game. We show that the critical discount factor for stationary collusion on one of these allocations is higher when firms are asymmetric than when they are symmetric. Second, we analyze the Pareto-efficient subset of the set of sustainable stationary outcomes.

\subsubsection{Stationary Collusion on Pareto-Efficient Outcomes}

Let us first analyze the Pareto-optimal allocation of production between two firms with strictly asymmetric marginal costs, ignoring the issue of collusive sustainability.

Solving the following problem for every $\alpha \in[0,1]$ yields a simple characterization of 
all Pareto-efficient outcomes for the firms: ${ }^{19}$

$$
\max _{\left\{p, s_{1}\right\}}\left[s_{1} \pi_{1}(p)\right]^{\alpha}\left[\left(1-s_{1}\right) \pi_{2}(p)\right]^{1-\alpha} .
$$

The solution for each $\alpha$ is such that

$$
s_{1}=\alpha,
$$

and that the two firms' iso-profit lines are tangent:

$$
-s_{1} \frac{\pi_{1}^{\prime}(p)}{\pi_{1}(p)}=\left(1-s_{1}\right) \frac{\pi_{2}^{\prime}(p)}{\pi_{2}(p)}
$$

As $\alpha$ varies between 0 and 1 , the optimal market sharing rule $s_{1}$ varies between 0 and 1 , and the optimal price varies between $p_{2}^{m}$ and $p_{1}^{m}$.

Solving (6) for $s_{1}$ yields the following one-to-one correspondence:

$$
s^{O}(p)=\frac{\left(c_{2}-c_{1}\right) D(p)+\left(p-c_{2}\right) \pi_{1}^{\prime}(p)}{\left(c_{2}-c_{1}\right) D(p)} .
$$

As can be easily seen from $(6), s^{O}\left(p_{1}^{m}\right)=1, s^{O}\left(p_{2}^{m}\right)=0$ and $\frac{\partial s^{O}}{\partial p}(p)<0$ for all $p \in\left[p_{1}^{m}, p_{2}^{m}\right]$. The inverse function of $s^{O}:\left[p_{1}^{m}, p_{2}^{m}\right] \rightarrow[0,1]$ will be denoted by $p^{O}:[0,1] \rightarrow\left[p_{1}^{m}, p_{2}^{m}\right]$. The set of Pareto-efficient outcomes can then be defined as follows:

$$
P O \equiv\left\{(p, s) \in\left(c_{2}, \bar{p}\right) \times \Delta^{1} \mid p=p^{O}\left(s_{1}\right)\right\}
$$

Next, let us check for which discount factors the intersection between the set of Paretoefficient allocations, $P O$, and the set of sustainable allocations, $\Lambda(\delta)$, is non-empty.

Proposition 1 Let $n=2$ and $c_{1}<c_{2}$. Then, there exists a discount factor threshold $\widehat{\delta}>\frac{1}{2}$ such that

- $\Lambda(\delta) \cap P O=\varnothing$ if and only if $\delta<\widehat{\delta}$, and

- for $\delta \geq \widehat{\delta}$, there exists a market share threshold $\widehat{s}_{1}(\delta) \in(1-\delta, \delta]$ such that all outcomes $\left(p^{O}\left(s_{1}\right), s_{1}, 1-s_{1}\right)$ with $s_{1} \in\left[\widehat{s}_{1}(\delta), \delta\right]$ are both Pareto-efficient and sustainable, i.e. are elements of $\Lambda(\delta) \cap P O$.

Figure 2 illustrates the results of Proposition 1 in the space $\left(s_{1}, p\right)$, with the understanding that $s_{2}=1-s_{1}$. For $\delta=\widehat{\delta}$, the unique allocation in the intersection between $\Lambda(\delta)$ and $P O$ has $p=p^{O}(\widehat{\delta})$ and $s_{1}=\widehat{\delta}$. For $\delta^{\prime}>\widehat{\delta}$, all allocations such that $p=p^{O}\left(s_{1}\right)$

\footnotetext{
${ }^{19}$ See exercise 6.1 in Tirole (1988) for a detailed treatment of an equivalent problem.
} 
and $s_{1} \in\left[\widehat{s}_{1}\left(\delta^{\prime}\right), \delta^{\prime}\right]$ are both Pareto-efficient and sustainable. Note also that $\widehat{s}_{1}\left(\delta^{\prime}\right)$ is the lowest market share $s_{1}$ for which, given the discount factor $\delta^{\prime}$, firm 1 is willing to go along with collusion at price $p^{O}\left(s_{1}\right)$.

The result that $\widehat{\delta}>\frac{1}{2}$ is intuitive. For any outcome $(p, s) \in\left(c_{2}, \bar{p}\right) \times \Delta^{1}$ to be sustainable, it is necessary that $s_{1}<1$, otherwise firm 2 could profitably deviate. If $s_{1}<1$, however, then Pareto-efficiency for the firms requires that $p>p_{1}^{m}$. This in turn implies that for firm 1 , the short-term deviation profit $\pi_{1}\left(p_{1}^{m}\right)$ strictly exceeds the standalone collusive profit $\pi_{1}(p)$. To render deviations unprofitable for the low-cost firm, it is therefore necessary that its collusive market share $s_{1}$ strictly exceeds $1-\delta$ :

$$
s_{1}>1-\delta
$$

Moreover, to rule out profitable deviations of the the high-cost firm, it is necessary that

$$
1-s_{1} \geq 1-\delta
$$

Adding up (9) and (10) yields $\delta>\frac{1}{2}$.

The comparison with the situation in which costs are symmetric is straightforward. If $c_{1}=c_{2}$, then any allocation such that $p=p_{1}^{m}$ is Pareto-efficient for the firms. The discount factor threshold for some efficient collusion is hence $\frac{1}{2}$ : collusion at the common monopoly price is possible for any discount factor larger than or equal to this threshold if the firms split the market evenly, i.e. if $s_{1}=\frac{1}{2}$. Thus, it is more difficult to sustain efficient collusion if costs are asymmetric than if costs are symmetric.

\subsubsection{The Pareto Frontier of Sustainable Outcomes}

We now analyze the Pareto-efficient subset of the set of sustainable stationary outcomes for each discount factor, still restricting attention to the case $n=2$. This approach takes account of the methodological point, underlined by Harrington (1991), that an allocation only provides a sensible collusive outcome if it is indeed implementable by a self-enforcing agreement. By restricting attention to the set of sustainable collusive equilibria a priori, the firms automatically solve this implementation problem.

Proposition 2 Let $n=2$ and $c_{1}<c_{2}$. Then, the Pareto-efficient subset of the set of sustainable stationary collusive outcomes is

$$
\Omega(\delta)=\Lambda(\delta) \cap\left[P O \cup\left\{\left(p, s_{1}, 1-s_{1}\right) \mid s_{1}=\delta, p \in\left[p_{1}^{m}, p^{O}(\delta)\right)\right\}\right] .
$$




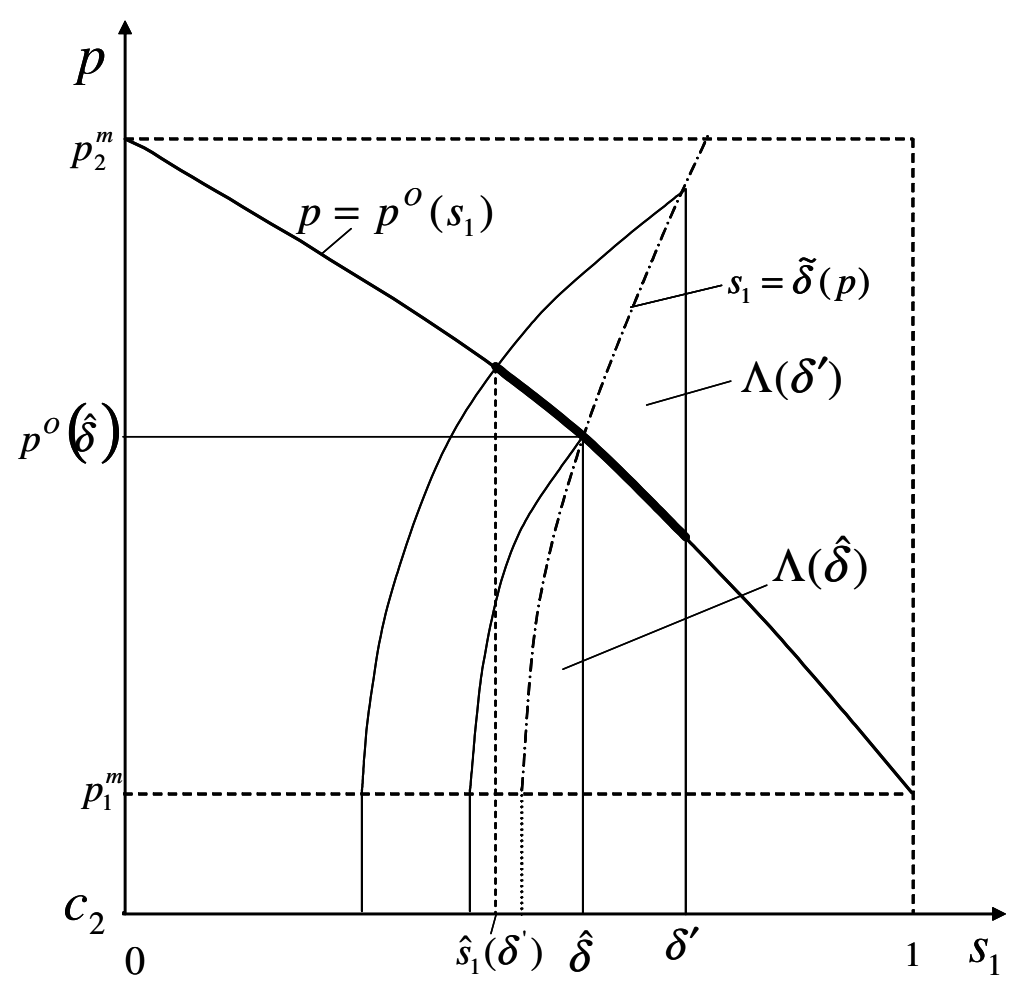

Figure 2: Efficient Stationary Collusion

Constrained Pareto-optimal outcomes thus either lie on firm 2's non-deviation constraint or/and are unconstrained Pareto optima. In the former case, prices lie between firm 1's monopoly price and $p^{O}(\delta)$. Figure 3 illustrates the sets of Pareto-undominated sustainable allocations for two different discount factors, $\delta_{1}$ and $\delta_{2}$, one below and one above $\widehat{\delta}$.

It is easy to understand the intuition behind these results graphically. First note that any allocation $(p, s) \in \Lambda(\delta)$ with $p<p_{1}^{m}$ is Pareto dominated by the allocation $\left(p_{1}^{m}, s\right)$, which is also included in $\Lambda(\delta)$; similarly, any allocation $(p, s) \in \Lambda(\delta)$ with $p>p_{2}^{m}$ is Pareto dominated by the allocation $\left(p_{2}^{m}, s\right) \in \Lambda(\delta)$. Therefore, we can restrict attention to sustainable allocations with $p \in\left[p_{1}^{m}, p_{2}^{m}\right]$. For such prices, firm 1's iso-profit lines in the $\left(s_{1}, p\right)$ space are strictly increasing and concave; in fact, for $p \geq p_{1}^{m}$, the iso-profit curve for profit level $(1-\delta) \pi_{1}\left(p_{1}^{m}\right)$ coincides with $C_{1}(\delta)$. Firm 1's payoff increases in the southeast direction, as firm 1 prefers a higher market share $s_{1}$ and prices closer to its own monopoly price. For prices below $p_{2}^{m}$, firm 2's iso-profit lines in the $\left(s_{1}, p\right)$ space are increasing and convex. For allocations with $p<p^{O}\left(s_{1}\right)$ they are flatter than, for allocations such that $p=p^{O}\left(s_{1}\right)$ tangent to, and for allocations such that $p>p^{O}\left(s_{1}\right)$ steeper than the iso-profit 


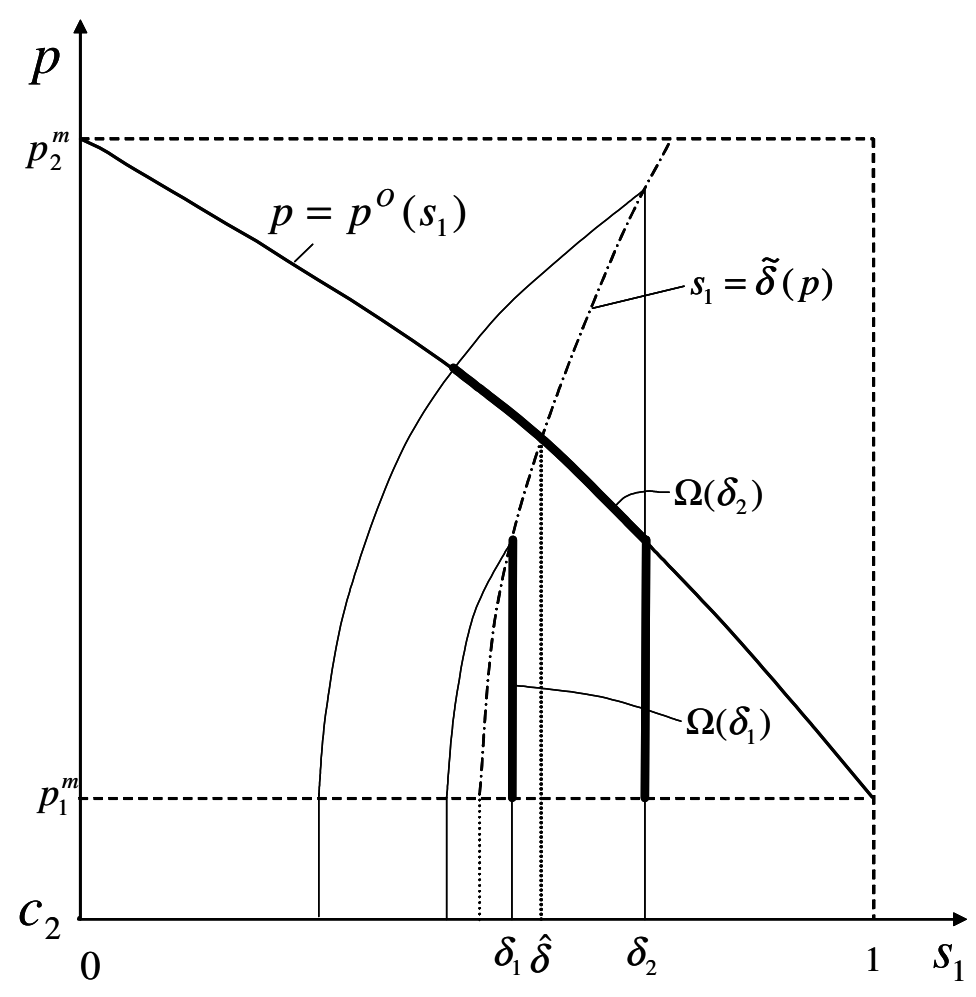

Figure 3: The Pareto Frontier of Sustainable Allocations

lines of firm 1. Moreover, firm 2's payoff increases in the northwest direction: firm 2 prefers a higher market share $s_{2}=1-s_{1}$ and prices closer to $p_{2}^{m}$.

Having said this, it is straightforward to exclude sustainable allocations with $p>$ $p^{O}\left(s_{1}\right)$ from any $\Omega(\delta)$ : moving along firm 1's iso-profit curve towards $p^{O}\left(s_{1}\right)$ always increases firm 2's profits without hindering collusive sustainability. Now consider any allocation where $p<p^{O}(s)$. If firms are able to move northeast along firm 1's iso-profit line without violating sustainability, a Pareto improvement within $\Lambda(\delta)$ is attainable: the high-cost firm is strictly better off thanks to the price increase although its market share $\left(1-s_{1}\right)$ is lower. The only sustainable allocations with $p<p^{O}\left(s_{1}\right)$ that are undominated are then those for which the high-cost firm's non-deviation constraint is binding, i.e. $s_{1}=\delta$, so that no further northeast moves are feasible. Finally, unconstrained Pareto optimal allocations are obviously undominated if sustainable. For $\delta \geq \widehat{\delta}$, the set of Pareto undominated sustainable allocations therefore always includes part of the set PO.

Finally, note that for sufficiently high discount factors, there can exist subgame perfect equilibria with non-stationary paths that Pareto-dominate (for the firms) allocations in $\Omega(\delta)$. While a full analysis of collusion on non-stationary paths is beyond the scope of 
this paper, let us illustrate this point by means of an example.

In the case of two firms, consider the following collusive outcome: the firms set $p_{1}^{m}$ in even periods and $p_{2}^{m}$ in odd periods, and firm $i$ makes all the sales in periods with price $p_{i}^{m}$. Starting from $t=0$, firm 1's average discounted payoff is $\frac{1}{1+\delta} \pi_{1}\left(p_{1}^{m}\right)$ and firm 2 's average discounted payoff is $\frac{\delta}{1+\delta} \pi_{2}\left(p_{2}^{m}\right)$. As can be easily checked, if $\delta=\frac{3}{4}$, then this agreement is sustainable, ${ }^{20}$ and the firms' average discounted payoffs are $\frac{4}{7} \pi_{1}\left(p_{1}^{m}\right)$ and $\frac{3}{7} \pi_{2}\left(p_{2}^{m}\right)$, respectively.

It is also easy to check that $\left(p^{O}\left(\frac{4}{7}\right), \frac{4}{7}, \frac{3}{7}\right) \in \Omega\left(\frac{3}{4}\right)$ whenever $\pi_{1}\left(p^{O}\left(\frac{4}{7}\right)\right) \geq \frac{7}{16} \pi_{1}\left(p_{1}^{m}\right)$. Suppose that this is indeed the case. Then, the allocation $\left(p^{O}\left(\frac{4}{7}\right), \frac{4}{7}, \frac{3}{7}\right)$ belongs to $\Omega\left(\frac{3}{4}\right)$ but the agreement with alternating monopolies described above is also sustainable and yields higher discounted payoffs for both firms.

The stationarity assumption hence restricts the scope of the analysis of efficient collusion. It does not, however, drive our results when comparing the discount factor thresholds for some collusion under cost symmetry and under cost asymmetry, nor does it drive our basic points concerning the collusion facilitating impact of side payments in the presence of cost asymmetry; see proposition A2 in the appendix and its discussion in footnote 16.

\section{Collusion with Side Payments}

Side payments are often ruled out in the literature on collusion, ${ }^{21}$ since antitrust law forbids overt monetary transfers in most jurisdictions. Nonetheless, as shown by the examples in the introduction, cartel agreements sometimes include side payments. In the following analysis, there are no restrictions at all on side payments. This is clearly an extreme case that does not reflect reality, yet it allows us to identify the mechanism by which cost asymmetry affects cartel sustainability when side payments are feasible. The main qualitative insight will carry over if the extent of side payments is limited.

\subsection{Sustainability}

We now consider an infinitely repeated interaction based on the following extensive form stage game. At the beginning of each period, the firms simultaneously quote prices. Then,

\footnotetext{
${ }^{20}$ The critical discount factor is $\frac{\sqrt{5}-1}{2}$.

${ }^{21}$ Exceptions include Jehiel (1992), as well as articles on collusion between privately informed firms such as Athey and Bagwell (2001).
} 
the lowest priced firm(s) serve(s) the entire demand. Finally, every firm with (strictly) positive sales unilaterally decides how much money to transfer to each of the other firms.

We can restrict attention to collusive outcomes such that firm 1 carries out all the production in every period: letting any other firm produce a positive quantity would not alter deviation profits, but lower (or at best leave unchanged if several firms have marginal cost $c_{1}$ ) total collusive profits, which can be shared by means of side payments. We then define a stationary collusive outcome with side payments by a vector $(p, S)$, where $p \in\left(c_{2}, \bar{p}\right)$ is the collusive market price and $S=\left(S_{1}, S_{2}, \ldots, S_{n}\right) \in \Delta^{n-1}$ is the vector of profit shares. In every period, all firms quote price $p$, firm 1 serves the entire demand $D(p)$, and finally pays $S_{i} \pi_{1}(p)$ to each firm $i \neq 1$.

Note that firm 1 has no reason to make positive side payments to firms with marginal costs above (or equal to) $p$, since those firms cannot credibly threaten to undercut the collusive price. Hence, only firms that belong to the previously defined set $A(p)=\left\{i \mid c_{i}<p\right\}$ need to receive positive transfers to prevent deviations: $S_{i}=0$ for all $i \notin A(p){ }^{22}$

As shown in section 3 , a security level penal code exists for any $\delta \in(0,1)$ in the absence of side payments. Since firms cannot be punished more severely than that in the periods following a deviation, there is no point in introducing side payments on punishment paths.

Firm 1's optimal one-shot deviation from the collusive outcome is to charge $\min \left[p, p_{1}^{m}\right]$ and refuse all side payments. The low-cost firm's non-deviation constraint is thus

$$
\pi_{1}\left(\min \left[p, p_{1}^{m}\right]\right) \leq \frac{1}{1-\delta} S_{1} \pi_{1}(p)
$$

The optimal one-shot deviation of any firm $i \in A(p) \backslash 1$ would be to slightly undercut $p$ if $p \leq p_{i}^{m}$, or to charge $p_{i}^{m}$ otherwise. ${ }^{23}$ Such a deviation would not only trigger the start of $i$ 's punishment in the next period, but also make $i$ lose the side payment from firm 1

\footnotetext{
${ }^{22} \mathrm{As}$ in the analysis without side payments, we could specifiy that on the collusive path $p_{i}^{t}=p_{i}^{m}$ for all $t$ if $i \notin A(p)$. This would not affect our results.

${ }^{23}$ It is obvious that the deviator has no incentive to make side payments.
} 
in the deviation period. ${ }^{24}$ The non-deviation constraint of any firm $i \in A(p) \backslash 1$ is hence

$$
\pi_{i}\left(\min \left[p, p_{i}^{m}\right]\right) \leq \frac{1}{1-\delta} S_{i} \pi_{1}(p) .
$$

A collusive outcome $(p, S)$ is then sustainable if and only if conditions $\left(D_{i}\right)$ are satisfied for all firms $i \in A(p)$, and $S_{i}=0$ for all $i \notin A(p)$. The implied necessary and sufficient condition on the discount factor for collusion at price $p$ is:

$$
\delta \geq \widetilde{\delta}^{T}(p)
$$

where

$$
\widetilde{\delta}^{T}(p) \equiv \frac{\sum_{i \in A(p)} \frac{\pi_{i}\left(\min \left[p, p_{i}^{m}\right]\right)}{\pi_{1}(p)}-1}{\sum_{i \in A(p)} \frac{\pi_{i}\left(\min \left[p, p_{i}^{m}\right]\right)}{\pi_{1}(p)}} .
$$

The following proposition compares the critical discount factor for collusion with side payments to the critical discount factor for collusion without side payments.

Proposition 3 Consider any $p \in\left(c_{2}, \bar{p}\right)$. Then, the critical discount factors $\widetilde{\delta}^{T}(p)$ defined in (11) and $\widetilde{\delta}(p)$ defined in (3) may be ranked as follows:

- If $c_{i}>c_{1}$ for some $i \in A(p)$, then $\widetilde{\delta}^{T}(p)<\widetilde{\delta}(p)$.

- If $c_{i}=c_{1}$ for all $i \in A(p)$, then $\widetilde{\delta}^{T}(p)=\widetilde{\delta}(p)$.

These results are intuitive. First, if all active firms have symmetric marginal costs (and there are no fixed costs), then no advantage can be derived from allocating production. Whether all the production is carried out by firm 1 and each firm $i \in A(p)$ then receives a share $S_{i}$ of $\pi_{1}(p)$, or each firm $i \in A(p)$ produces and sells a share $s_{i}=S_{i}$ of total output $D(p)$ makes no difference for the active firms' collusive or deviation profits. Hence, the feasibility of side payments is irrelevant.

If the active firms have asymmetric costs, side payments facilitate collusion. This is true because any firm $i \in A(p)$ with $c_{i}>c_{1}$ has less to gain when deviating from the

\footnotetext{
${ }^{24}$ Since we assume that only firm(s) with positive sales can make side payments, we automatically obtain a kind of "within period" punishment: whenever firm 1 is undercut by a deviator, it reneges on its side payments. If instead firm 1 could make side payments even after being undercut, an optimal punishment code would need to have the following feature: If on the collusive path firm 1 reneges on its side payment after observing a deviation by a firm $i \neq 1$, then this will not trigger firm 1's punishment but firm $i$ 's. It would then be optimal for firm 1 to indeed refuse side payments after a deviation by any other firm.
} 
collusive outcome $(p, S)$ than when deviating under collusion without side payments from an outcome with the same price $p$ and $s=S$. In the presence of side payments, compliance permits a less efficient firm to benefit from the cost advantage of firm 1, while the firm would have to rely on its own inferior production technology when deviating.

It is worth noting that the threshold $\widetilde{\delta}^{T}(p)$ is increasing for all $p \in\left(c_{2}, \bar{p}\right)$. For $p<p_{1}^{m}$, a price reduction alleviates the non-deviation constraints of active firms with marginal costs above $c_{1} \cdot{ }^{25}$ In fact, if $c_{1}<c_{2}$, then $\widetilde{\delta}^{T}(p) \rightarrow 0$ as $p \rightarrow c_{2}$, so that some collusion is sustainable for any $\delta>0$. For $p>p_{1}^{m}$, a price rise increases the deviation incentives of all active firms: $\frac{\pi_{i}\left(\min \left[p, p_{i}^{m}\right]\right)}{\pi_{1}(p)}$ is increasing in $p$ for all $i \in A(p)$ in this case. Finally, for all $p \in\left(c_{2}, \bar{p}\right)$, a price increase may lead to a rise in the number of active firms, which clearly raises the critical discount factor.

Figure 4 illustrates the set of sustainable outcomes for some discount factor $\delta^{\prime} \in$ $\left(\widetilde{\delta}^{T}\left(p_{1}^{m}\right), \widetilde{\delta}^{T}\left(p_{2}^{m}\right)\right)$ if $n=2$ and $c_{1}<c_{2}$. Since $n=2$, the vector $\left(p, S_{1}\right)$ fully defines a collusive outcome. The set of sustainable outcomes for discount factor $\delta^{\prime}$ then includes all $\left(p, S_{1}\right)$ that are (i) on or right of the line labelled $D_{1}\left(\delta^{\prime}\right)$ along which firm 1 is indifferent between complying and deviating, and (ii) on or left of the line labelled $D_{2}\left(\delta^{\prime}\right)$ along which firm 2 is indifferent between complying and deviating. Note that $D_{2}\left(\delta^{\prime}\right)$ lies to the right of the line defined by $S_{1}=\delta^{\prime}$ : the less efficient firm is willing to comply even if its profits share $1-S_{1}$ is less than $1-\delta^{\prime}$ because compliance allows the firm to benefit from firm 1's cost advantage.

As already noted by Bernheim and Whinston (1990), this is related to collusion under multi-market contact. When each firm has a marginal cost advantage in one market, multi-market contact facilitates collusion: by shifting sales towards the most efficient firm in each market, collusive profits go up, and the gains from deviating fall. A similar mechanism is at work here: side payments allow a shift of sales to the most efficient firm, which raises collusive profits and decreases the deviation gains of less efficient firms.

\subsection{Pareto-Efficient Collusion with Side Payments}

\subsubsection{Collusion on Pareto-Efficient Outcomes}

With side payments, any collusive outcome such that $p=p_{1}^{m}$ and firm 1 carries out all the production is efficient, since firms cannot jointly gain by either changing the price or reallocating production. The unconstrained Pareto profit frontier thus consists of all

\footnotetext{
${ }^{25}$ It is easy to check that if $c_{i}>c_{1}$, then $\frac{\pi_{i}\left(\min \left[p, p_{i}^{m}\right]\right)}{\pi_{1}(p)}$ is strictly increasing in $p$ for all $p \in\left(c_{2}, \bar{p}\right)$.
} 


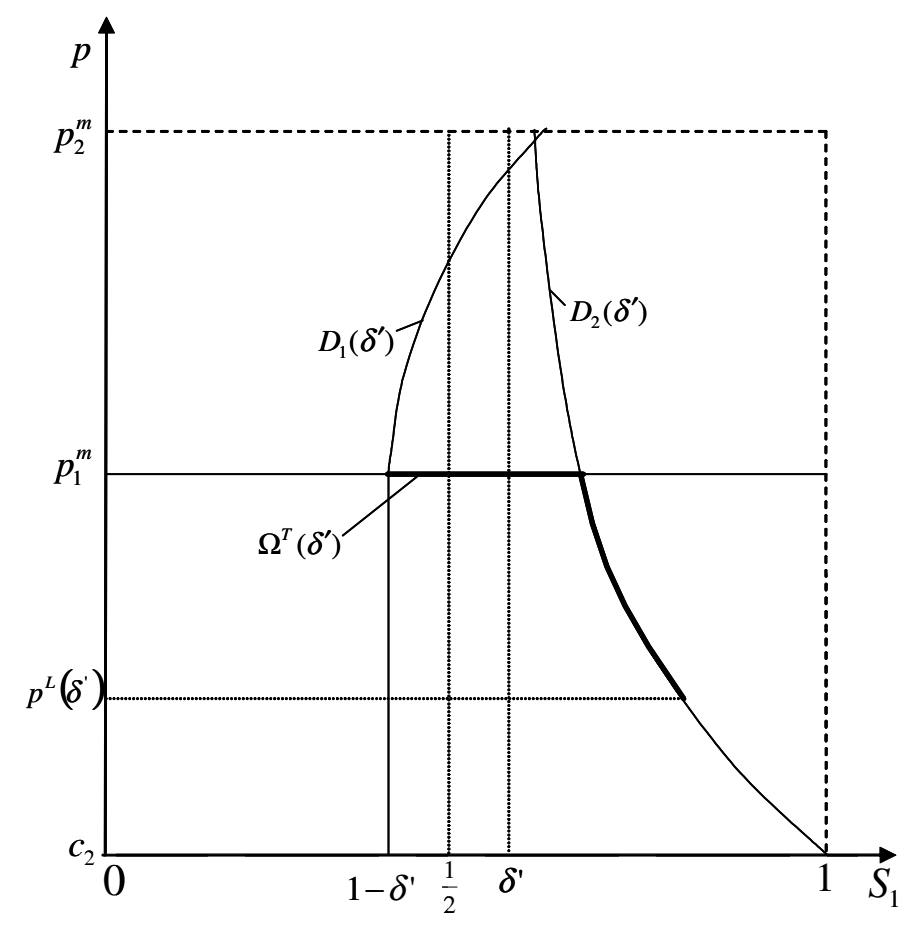

Figure 4: Sustainable Collusive Ouctomes with Side Payments

possible divisions of $\pi_{1}\left(p_{1}^{m}\right)$. The critical discount factor for collusion on a Pareto-efficient outcome with side payments is simply equal to $\widetilde{\delta}^{T}\left(p_{1}^{m}\right)$.

Under cost asymmetry, more precisely if $c_{i}>c_{1}$ for some $i \in A\left(p_{1}^{m}\right), \widetilde{\delta}^{T}\left(p_{1}^{m}\right)$ lies strictly below the critical discount factor for collusion on a Pareto-efficient outcome without side payments. First, by Proposition 3, if $c_{i}>c_{1}$ for some $i \in A\left(p_{1}^{m}\right)$, then $\widetilde{\delta}^{T}\left(p_{1}^{m}\right)<\widetilde{\delta}\left(p_{1}^{m}\right)$. Second, without side payments, for a statically Pareto-efficient outcome to be sustainable, it is necessary that the price exceeds $p_{1}^{m} .{ }^{26}$ This implies that the discount factor threshold for efficient collusion without side payments lies strictly above $\widetilde{\delta}\left(p_{1}^{m}\right)$, which, as just argued, already exceeds $\widetilde{\delta}^{T}\left(p_{1}^{m}\right)$.

Proposition 3 also implies that if $c_{i}>c_{1}$ for some $i \in A\left(p_{1}^{m}\right)$, then $\widetilde{\delta}^{T}\left(p_{1}^{m}\right)<\widetilde{\delta}\left(p_{1}^{m}\right)=$ $\frac{m\left(p_{1}^{m}\right)-1}{m\left(p_{1}^{m}\right)}$. This means that $\widetilde{\delta}^{T}\left(p_{1}^{m}\right)$ is smaller than the threshold for efficient collusion, that is, collusion on the common monopoly price, between $m\left(p_{1}^{m}\right)$ symmetric firms.

Consider $n=2$ for example. If $c_{1}=c_{2}$, the critical discount factor for efficient collusion

\footnotetext{
${ }^{26}$ Without side payments, any statically Pareto-efficient outcome with price $p_{1}^{m}$ must assign $s_{i}=0$ to firm $i$ if $c_{i}>c_{1}$. This means that any firm $i \in A\left(p_{1}^{m}\right)$ with $c_{i}>c_{1}$ could profitably deviate from such an outcome. All other Pareto-efficient outcomes must involve prices strictly above $p_{1}^{m}$ : if the price were below $p_{1}^{m}$, all firms could gain from moving to an outcome with the same market shares but price $p_{1}^{m}$.
} 
is $\frac{1}{2}$. If $c_{1}<c_{2}$, the critical discount factor for collusion on a Pareto-efficient allocation

lies strictly below $\frac{1}{2}$ if side payments are feasible, but strictly above $\frac{1}{2}$ if side payments are impossible (see also Proposition 1).

Finally, note that the comparison between the critical discount factors for efficient collusion with side payments under cost symmetry and under cost asymmetry would be less straightforward if firms used "standard" trigger strategies instead of optimal punishments. Cost asymmetry would have two countervailing effects in that case: on the one hand, it would increase the punishment payoff of the most efficient firm and thereby hinders collusion, but on the other hand, since side payments are feasible, cost asymmetry would tend to facilitate collusion by alleviating the inefficient firms' non-deviation constraints.

\subsubsection{The Pareto Frontier of Sustainable Outcomes}

We now analyze the Pareto-efficient subset of the set of sustainable outcomes with side payments. For simplicity, we restrict attention to $n=2$, as in the corresponding analysis without side payments. The set of unconstrained Pareto-efficient outcomes then consists of all $(p, S) \in\left(c_{2}, \bar{p}\right) \times \Delta^{1}$ such that $p=p_{1}^{m}$. Obviously, if any unconstrained efficient outcome is sustainable, then this outcome is also part of the Pareto-efficient subset of the set of sustainable outcomes. As the following proposition shows, the constrained Pareto frontier moreover always includes one or several outcomes such that firm 2's non-deviation constraint is binding and the price lies strictly below $p_{1}^{m} \cdot{ }^{27}$

Proposition 4 Let $n=2$ and $c_{1}<c_{2}$. For every $\delta$, define $p^{U}(\delta)$ as the highest sustainable price, uniquely defined by the implicit condition $\widetilde{\delta}^{T}\left(p^{U}(\delta)\right)=\delta$. Moreover, assume that $2\left[D^{\prime}(p)\right]^{2}>D(p) D^{\prime \prime}(p)$ for $p \in\left(c_{2}, p_{1}^{m}\right)$. There then exists, for every $\delta$, a unique price $p^{L}(\delta) \in\left[c_{2}, p_{1}^{m}\right)$ such that the following statements are true.

- If $\delta \geq \widetilde{\delta}^{T}\left(p_{1}^{m}\right)$, then the Pareto-efficient subset of the set of sustainable stationary collusive outcomes with side payments is equal to

$$
\begin{aligned}
\Omega^{T}(\delta)= & \left\{\left(p, S_{1}, 1-S_{1}\right) \mid p=p_{1}^{m}, S_{1} \in\left[1-\delta, 1-(1-\delta) \frac{\pi_{2}(p)}{\pi_{1}(p)}\right]\right\} \\
& \cup\left\{(p, S) \in\left(c_{2}, \bar{p}\right) \times \Delta^{1} \mid p \in\left[p^{L}(\delta), p_{1}^{m}\right], S_{1}=1-(1-\delta) \frac{\pi_{2}(p)}{\pi_{1}(p)}\right\} .
\end{aligned}
$$

\footnotetext{
${ }^{27}$ To show that this is true, we do not need the assumption $2\left[D^{\prime}(p)\right]^{2}>D(p) D^{\prime \prime}(p)$ made in proposition 4. The role of this assumption is to guarantee the existence of a unique threshold $p^{L}(\delta)$ as characterized in the proposition.
} 
- If $\delta<\widetilde{\delta}^{T}\left(p_{1}^{m}\right)$, then the Pareto-efficient subset of the set of sustainable stationary collusive outcomes with side payments is equal to

$$
\Omega^{T}(\delta)=\left\{(p, S) \in\left(c_{2}, \bar{p}\right) \times \Delta^{1} \mid p \in\left[\min \left\{p^{L}(\delta), p^{U}(\delta)\right\}, p^{U}(\delta)\right], S_{1}=1-(1-\delta) \frac{\pi_{2}(p)}{\pi_{1}(p)}\right\} .
$$

Figure 4 illustrates the Pareto-efficient subset of the set of sustainable collusive outcomes for some discount factor $\delta^{\prime}>\widetilde{\delta}^{T}\left(p_{1}^{m}\right)$. Why are outcomes with prices strictly below $p_{1}^{m}$ part of the constrained Pareto frontier? This is because firm 1's preferred sustainable outcome is not the efficient outcome at price $p_{1}^{m}$ for which $S_{1}$ is as large as possible without provoking a deviation by firm 2. In fact, firm 1 prefers to move to a price strictly below $p_{1}^{m}$ : a marginal move has a negative second-order effect on $\pi_{1}\left(p_{1}^{m}\right)$, but this effect can be more than offset by a positive first-order effect on $S_{1}$, since the price reduction alleviates firm 2's no-deviation constraint. The shapes of the constrained Pareto frontiers with and without side payments thus bear some resemblance. In both cases, the constrained Pareto frontier consists (i) of all unconstrained Pareto-efficient outcomes that are sustainable, and (ii) of some outcomes at which firm 1's market (respectively, profit) share is as large as possible given the price and the discount factor, and the price lies below the Pareto-efficient level $\left(p^{O}(\delta)\right.$ or $p_{1}^{m}$, respectively).

\section{Concluding Remarks}

By using optimal punishments and allowing for side payments, this paper addresses two largely unexplored aspects in the existing literature on collusion between cost asymmetric firms. We have derived three main results: (i) Without side payments, some collusion is sustainable under cost asymmetry whenever collusion is sustainable under cost symmetry. (ii) Without side payments, efficient collusion is more difficult when costs are asymmetric. (iii) With side payments, cost asymmetries facilitate collusion. The key policy implication is that the feasibility of side payments between cartel members plays a particularly important role when firms have asymmetric cost structures.

We characterize the maximum scope for collusion in the textbook model of Bertrand competition under cost asymmetry. Interesting avenues for future research may be to explicitly model the costs associated with disguising side transfers, or to use more general cost sstructure to check the robustness of our results. 


\section{A Appendix}

Proof of Proposition 1: Let $n=2, c_{1}<c_{2}$, and $(p, s) \in\left(c_{2}, \bar{p}\right) \times \Delta^{1}$. Then, $(p, s) \in$ $P O \cap \Lambda(\delta)$ if and only if

$$
\begin{aligned}
p & =p^{O}\left(s_{1}\right), \\
s_{1} \pi_{1}\left(p^{O}\left(s_{1}\right)\right) & \geq(1-\delta) \pi_{1}\left(p_{m}^{1}\right), \text { and } \\
s_{1} & \leq \delta .
\end{aligned}
$$

The first condition ensures that $(p, s) \in P O$. The latter two conditions are the nondeviation constraints $\left(C_{1}\right)$ and $\left(C_{2}\right)$ when substituting $p^{O}\left(s_{1}\right)$ for $p$ and using the fact that $p^{O}\left(s_{1}\right) \in\left[p_{1}^{m}, p_{2}^{m}\right]$ for all $s_{1} \in[0,1]$.

Firm 1's per period profit $s_{1} \pi_{1}\left(p^{O}\left(s_{1}\right)\right)$ is equal to 0 for $s_{1}=0$ and equal to $\pi_{1}\left(p_{m}^{1}\right)$ for $s_{1}=1$. Moreover, since $\frac{\partial \pi_{1}}{\partial p}<0$ for $p>p_{1}^{m}$ and $\frac{\partial p^{O}}{\partial s_{1}}<0, s_{1} \pi_{1}\left(p^{O}\left(s_{1}\right)\right)$ is strictly increasing in $s_{1}$ for all $s_{1} \in[0,1]$. These observations imply that firm 1 's non-deviation constraint in (13) is satisfied if and only if

$$
s_{1} \geq \widehat{s}_{1}(\delta)
$$

where the one-to-one correspondence $\widehat{s}_{1}(\cdot):(0,1) \rightarrow(0,1)$ is implicitly defined by the following condition: ${ }^{28}$

$$
\widehat{s}_{1}(\delta) \pi_{1}\left(p^{O}\left(\widehat{s}_{1}(\delta)\right)\right)=(1-\delta) \pi_{1}\left(p_{m}^{1}\right)
$$

It is easy to see that $\lim _{\delta \rightarrow 0} \widehat{s}_{1}(\delta)=1, \lim _{\delta \rightarrow 1} \widehat{s}_{1}(\delta)=0$, and $\frac{\partial \widehat{s}_{1}}{\partial \delta}<0$ for all $\delta \in(0,1)$. There therefore exists a unique $\widehat{\delta}$ such that

$$
\widehat{s}_{1}(\widehat{\delta})=\widehat{\delta}
$$

Since $\pi_{1}\left(p_{m}^{1}\right)>\pi_{1}\left(p^{O}\left(s_{1}\right)\right)$ for all $s_{1} \in[0,1)$, it follows from the definition of $\widehat{s}_{1}(\delta)$ in (16) that $\widehat{s}_{1}(\delta)>1-\delta$ for all $\delta \in(0,1)$. It directly follows that the threshold $\widehat{\delta}$ as defined by condition (17) exceeds $\frac{1}{2}$ :

$$
\widehat{\delta}>\frac{1}{2}
$$

\footnotetext{
${ }^{28}$ Indeed, $\widehat{s}_{1}(\delta)$ is closely related to the lower bound on firm 1's market share derived in section 4.1:

$$
\widehat{s}_{1}(\delta)=\widetilde{s}_{1}\left(p^{O}(\delta), \delta\right)
$$
}


Now suppose $\delta<\widehat{\delta}$. Then, since $\frac{\partial \widehat{s}_{1}}{\partial \delta}<0$,

$$
\widehat{s}_{1}(\delta)>\delta
$$

Hence, conditions (15) and (14) are incompatible, which implies that $P O \cap \Lambda(\delta)=\varnothing$.

If $\delta \geq \widehat{\delta}$, on the other hand, then $\widehat{s}_{1}(\delta) \leq \delta$. In this case, $P O \cap \Lambda(\delta)$ is non-empty and contains all allocations $(p, s) \in\left(c_{2}, \bar{p}\right) \times \Delta^{1}$ such that $p=p^{O}\left(s_{1}\right)$ and $s_{1} \in\left[\widehat{s}_{1}(\delta), \delta\right]$. Q.E.D.

Proof of Proposition 2: Let $n=2$ and $c_{1}<c_{2}$. Define the payoff functions $V_{i}\left(p, s_{1}\right)$ for $i=1,2$ as follows:

$$
\begin{aligned}
V_{1}\left(p, s_{1}\right) & \equiv s_{1} \pi_{1}(p) \\
V_{2}\left(p, s_{1}\right) & \equiv\left(1-s_{1}\right) \pi_{2}(p) .
\end{aligned}
$$

Then, the set of sustainable allocations $\Lambda(\delta)$ consists of all $(p, s) \in\left(c_{2}, \bar{p}\right) \times \Delta^{1}$ such that the following two non-deviation conditions are satisfied:

$$
\begin{aligned}
& V_{1}\left(p, s_{1}\right) \geq(1-\delta) \pi_{1}\left(\min \left[p, p_{1}^{m}\right]\right) \\
& V_{2}\left(p, s_{1}\right) \geq(1-\delta) \pi_{2}\left(\min \left[p, p_{2}^{m}\right]\right)
\end{aligned}
$$

An allocation $(p, s) \in \Omega(\delta)$ if and only if $(p, s) \in \Lambda(\delta)$ and there does not exist any $\left(p^{\prime}, s^{\prime}\right) \in \Lambda(\delta)$ such that $V_{i}\left(p^{\prime}, s^{\prime}\right) \geq V_{i}(p, s)$ for all $i \in\{1,2\}$ and $V_{i}\left(p^{\prime}, s^{\prime}\right)>V_{i}(p, s)$ for at least one $i \in\{1,2\}$.

Obviously, if $(p, s) \in \Lambda(\delta) \cap P O$, i.e. if $(p, s)$ is an unconstrained Pareto optimum and sustainable for discount factor $\delta$, then $(p, s) \in \Omega(\delta)$.

For all $V \in\left(0, \pi_{1}\left(p_{1}^{m}\right)\right)$, define the contour sets of firm 1's payoff as ${ }^{29}$

$$
C(V) \equiv\left\{\left(p, s_{1}\right) \mid s_{1}=\eta(p ; V), p \in\left[\min \left\{p \mid \pi_{1}(p) \geq V\right\}, \max \left\{p \mid \pi_{1}(p) \geq V\right\}\right]\right\}
$$

where

$$
\eta(p ; V) \equiv \frac{V}{\pi_{1}(p)} .
$$

Suppose that $(\widetilde{p}, \widetilde{s}) \in \Lambda(\delta)$ for the remainder of this proof, and let $\widetilde{V} \equiv V_{1}\left(\widetilde{p}, \widetilde{s}_{1}\right)$. Then, $\widetilde{s}_{1}=\eta(\widetilde{p} ; \widetilde{V}) \in(0,1)$ and $\left(\widetilde{p}, \widetilde{s}_{1}\right) \in C(\widetilde{V})$. Now consider any

\footnotetext{
${ }^{29}$ Assumption A3 implies that for any $V \in\left(0, \pi_{1}\left(p_{1}^{m}\right)\right)$ there exists a unique $\min \left\{p \mid \pi_{1}(p) \geq V\right\} \in$ $\left(c_{1}, p_{1}^{m}\right)$ and a unique $\max \left\{p \mid \pi_{1}(p) \geq V\right\} \in\left(p_{1}^{m}, \bar{p}\right)$, and that $\pi_{1}(p)>V$ for all $p \in$ $\left(\min \left\{p \mid \pi_{1}(p) \geq V\right\}, \max \left\{p \mid \pi_{1}(p) \geq V\right\}\right)$. Note also that if $\left(p, s_{1}\right) \in C(V)$, then $s_{1} \in(0,1]$.
} 
$p^{\prime} \in\left[\min \left\{p \mid \pi_{1}(p) \geq \widetilde{V}\right\}, \max \left\{p \mid \pi_{1}(p) \geq \widetilde{V}\right\}\right] \cdot{ }^{30}$ Then, $(p, \eta(p ; \widetilde{V})) \in C(\widetilde{V})$ for all $p$ between $\widetilde{p}$ and $p^{\prime}$, and

$$
V_{2}\left(p^{\prime}, \eta\left(p^{\prime} ; \widetilde{V}\right)\right)-V_{2}\left(\widetilde{p}, \widetilde{s}_{1}\right)=\int_{\widetilde{p}}^{p^{\prime}} \frac{d V_{2}}{d p}(p, \eta(p ; \widetilde{V})) d p
$$

where

$$
\frac{d V_{2}}{d p}(p, \eta(p ; \widetilde{V}))=(1-\eta(p ; \widetilde{V})) \pi_{2}^{\prime}(p)-\underbrace{\left(-\eta(p ; \widetilde{V}) \frac{\pi_{1}^{\prime}(p)}{\pi_{1}(p)}\right)}_{=\eta^{\prime}(p ; \widetilde{V})} \pi_{2}(p) .
$$

Recall from section 4.2.1 that for any $s_{1} \in[0,1]$,

$$
p^{O}\left(s_{1}\right):\left(1-s_{1}\right) \pi_{2}^{\prime}\left(p^{O}\left(s_{1}\right)\right)=-s_{1} \frac{\pi_{1}^{\prime}\left(p^{O}\left(s_{1}\right)\right)}{\pi_{1}\left(p^{O}\left(s_{1}\right)\right)} \pi_{2}\left(p^{O}\left(s_{1}\right)\right) .
$$

Since $p^{O}\left(s_{1}\right) \in\left[p_{1}^{m}, p_{2}^{m}\right]$ for all $s_{1} \in[0,1]$, and $\pi_{i}(p)$ is strictly concave with maximizer $p_{i}^{m}$, the following inequalitites, which will play a key role in the remainder of this proof, hold:

$$
\begin{aligned}
& \frac{d V_{2}}{d p}(p, \eta(p ; \widetilde{V}))<0 \text { if } p>p^{O}(\eta(p ; \widetilde{V})), \\
& \frac{d V_{2}}{d p}(p, \eta(p ; \widetilde{V}))>0 \text { if } p<p^{O}(\eta(p ; \widetilde{V})) .
\end{aligned}
$$

We first show that if $\widetilde{s}_{1}=\delta$ and $p_{1}^{m} \leq \widetilde{p}<p^{O}(\delta)$, then $(\widetilde{p}, \widetilde{s}) \in \Omega(\delta)$. Suppose not. Then there exists an allocation $\left(p^{\prime}, s^{\prime}\right) \in \Lambda(\delta)$ that Pareto-dominates $(\widetilde{p}, \widetilde{s})$ for the firms. First, it is easy to see that $p^{\prime}<\widetilde{p}$. Since $p_{1}^{m} \leq \widetilde{p}, \pi_{1}\left(p^{\prime}\right) \leq \pi_{1}(\widetilde{p})$ if $p^{\prime} \geq \widetilde{p}$. Moreover, $\left(p^{\prime}, s^{\prime}\right) \in \Lambda(\delta)$ implies that $s_{1}^{\prime} \leq \delta$, otherwise firm 2's non-deviation constraint would be violated. Therefore, $V_{1}\left(p^{\prime}, s_{1}^{\prime}\right)<V_{1}\left(\widetilde{p}, \widetilde{s}_{1}\right)$ if $p^{\prime} \geq \widetilde{p}$ and $\left(p^{\prime}, s^{\prime}\right) \neq(\widetilde{p}, \widetilde{s})$. Suppose therefore that $p^{\prime}<\widetilde{p}$. Next, we show that for any $p \in\left[p^{\prime}, \widetilde{p}\right], p<p^{O}(\eta(p ; \widetilde{V}))$. The concavity of $\pi_{1}$ implies that $\pi_{1}(p) \geq \min \left[\pi_{1}\left(p^{\prime}\right), \pi_{1}(\widetilde{p})\right]$. It follows from this that $\eta(p ; \widetilde{V}) \leq \delta$ : $s_{1}^{\prime} \leq \widetilde{s}_{1}=\delta$, otherwise firm 2's non-deviation constraint would be violated at $\left(p^{\prime}, s^{\prime}\right)$, and $\eta(p ; \widetilde{V})=\frac{\widetilde{V}}{\pi_{1}(p)}=\widetilde{s}_{1} \frac{\pi_{1}(\widetilde{p})}{\pi_{1}(p)} \leq \frac{V_{1}\left(p^{\prime}, s_{1}^{\prime}\right)}{\pi_{1}(p)}=s_{1}^{\prime} \frac{\pi_{1}\left(p^{\prime}\right)}{\pi_{1}(p)}$ by the requirement that $\left(p^{\prime}, s^{\prime}\right)$ Paretodominates $(\widetilde{p}, \widetilde{s})$. As $p^{O}(\cdot)$ is decreasing, $\eta(p ; \widetilde{V}) \leq \delta$ implies that $p^{O}(\delta) \leq p^{O}(\eta(p ; \widetilde{V}))$. Finally, since $\widetilde{p}<p^{O}(\delta)$, we can conclude that for any $p \in\left[p^{\prime}, \widetilde{p}\right], p<p^{O}(\eta(p ; \widetilde{V}))$. From $(24)$ it then follows that $\frac{d V_{2}}{d p}(p, \eta(p ; \widetilde{V}))>0$ for all $p \in\left[p^{\prime}, \widetilde{p}\right]$. Since $p^{\prime}<\widetilde{p}$, this implies that $\int_{\widetilde{p}}^{p^{\prime}} \frac{d V_{2}}{d p}(p, \eta(p)) d p<0$, so that, by $(20), V_{2}\left(p^{\prime}, \eta\left(p^{\prime} ; \widetilde{V}\right)\right)<V_{2}\left(\widetilde{p}, \widetilde{s}_{1}\right)$. Since $V_{1}\left(p^{\prime}, s_{1}^{\prime}\right) \geq V_{1}\left(\widetilde{p}, \widetilde{s}_{1}\right)$ only if $s_{1}^{\prime} \geq \eta\left(p^{\prime} ; \widetilde{V}_{1}\right)$ and $\frac{\partial V_{2}}{\partial s_{1}}<0$, this implies that $V_{2}\left(p^{\prime}, s_{1}^{\prime}\right)<$ $V_{2}\left(\widetilde{p}, \widetilde{s}_{1}\right)$, so that we have a contradiction. Hence, $(\widetilde{p}, \widetilde{s}) \in \Omega(\delta)$.

\footnotetext{
${ }^{30}$ Since $\widetilde{s}_{1} \in(0,1), \pi_{1}(\widetilde{p})>\widetilde{V}$. The set $\left[\min \left\{p \mid \pi_{1}(p) \geq \widetilde{V}\right\}, \max \left\{p \mid \pi_{1}(p) \geq \widetilde{V}\right\}\right]$ hence inludes prices both above and below $\widetilde{p}$.
} 
To prove the statement of the proposition, all that remains to be done is to exclude $(\widetilde{p}, \widetilde{s})$ that are neither in $P O$ nor such that $\widetilde{s}_{1}=\delta$ and $p_{1}^{m} \leq \widetilde{p}<p^{O}(\delta)$ from $\Omega(\delta)$. Let us distinguish between three different cases:

Case 1: $\widetilde{p}<p_{1}^{m}$

It is straightforward to see that $(\widetilde{p}, \widetilde{s}) \notin \Omega(\delta)$ in this case. First, $\left(p_{1}^{m}, \widetilde{s}\right) \in \Lambda(\delta)$ : the non-deviation constraints for collusion boil down to $1-\delta \leq \widetilde{s}_{1} \leq \delta$ at both allocations. Second, $V_{i}\left(p_{1}^{m}, \widetilde{s}\right)>V_{i}(p, \widetilde{s})$ for $i=1,2$.

Case 2: $\widetilde{p}>p^{O}\left(\widetilde{s}_{1}\right)$

In this case, (23) implies that a Pareto-improvement for the firms can be achieved locally by means of a small price decrease coupled with a marginal change in market shares so as to keep firm 1's payoff constant. Since $\pi_{i}\left(\min \left[p, p_{i}^{m}\right]\right)$ is non-decreasing in $p$ for $i=1,2$, such a Pareto-improvement can be achieved without leading to a violation of the non-deviation constraints, that is, within $\Lambda(\delta)$. We conclude that $(\widetilde{p}, \widetilde{s}) \notin \Omega(\delta)$.

Case 3: $p_{1}^{m} \leq \widetilde{p}<p^{O}\left(\widetilde{s}_{1}\right), \widetilde{s}_{1}<\delta$

In this case, by (24), the firms can achieve a Pareto-improvement locally by means of a marginal price increase coupled with a marginal increase in firm 1's market share so as to keep firm 1's payoff constant. Such a Pareto-improvement can be achieved within the set $\Lambda(\delta)$. First, firm 2's non-deviation constraint, which is $\widetilde{s}_{1} \leq \delta$ at $(\widetilde{p}, \widetilde{s})$, remains slack by continuity: $\widetilde{s}_{1}<\delta$ by assumption and $\eta(p ; \widetilde{V})$ is continuous in $p$. Second, since $p_{1}^{m} \leq \widetilde{p}$, firm 1's deviation profit is unaffected by a marginal price increase. Hence, $(\widetilde{p}, \widetilde{s}) \notin \Omega(\delta)$. Q.E.D.

Proof of Proposition 3: Let $p \in\left(c_{2}, \bar{p}\right)$. Recall that

$$
\widetilde{\delta}(p)=\frac{\sum_{i \in A(p)} \frac{\pi_{i}\left(\min \left[p, p_{i}^{m}\right]\right)}{\pi_{i}(p)}-1}{\sum_{i \in A(p)} \frac{\pi_{i}\left(\min \left[p, p_{i}^{m}\right]\right)}{\pi_{i}(p)}} .
$$

If $c_{i}=c_{1}$ for all $i \in A(p)$, then $\pi_{i}(p)=\pi_{1}(p)$ for all $i \in A(p)$. Hence, $\widetilde{\delta}(p)=\widetilde{\delta}^{T}(p)$.

If $c_{i}>c_{1}$ for some $i \in A(p)$, however, then $\pi_{i}(p)<\pi_{1}(p)$ for some $i \in A(p)$, while still $\pi_{i}(p) \leq \pi_{1}(p)$ for all $i \in A(p)$. Hence, $\sum_{i \in A(p)} \frac{\pi_{i}\left(\min \left[p, p_{i}^{m}\right]\right)}{\pi_{1}(p)}<\sum_{i \in A(p)} \frac{\pi_{i}\left(\min \left[p, p_{i}^{m}\right]\right)}{\pi_{i}(p)}$, which implies that $\widetilde{\delta}^{T}(p)<\widetilde{\delta}(p)$. Q.E.D.

Proof of Proposition 4: Let $n=2$ and $c_{1}<c_{2}$. Denote by $\Lambda^{T}(\delta)$ the set of sustainable stationary collusive outcomes with side payments:

$$
\Lambda^{T}(\delta) \equiv\left\{(p, S) \in\left(c_{2}, \bar{p}\right) \times \Delta^{1} \mid\left(D_{i}\right) \text { holds for } i=1,2\right\}
$$


Similarly, denote by $\Omega^{T}(\delta)$ the Pareto-efficient subset of $\Lambda^{T}(\delta)$ that we seek to characterize. $(p, S) \in \Omega^{T}(\delta)$ if and only if $(p, S) \in \Lambda^{T}(\delta)$ and there does not exist any $\left(p^{\prime}, S^{\prime}\right) \in \Lambda^{T}(\delta)$ that Pareto-dominates $(p, S)$ for the firms.

It is easy to the see that $\Omega^{T}(\delta)$ never includes any outcomes with $p>p_{1}^{m}$. First, if any given outcome $(p, S)$ with $p>p_{1}^{m}$ belongs to $\Lambda^{T}(\delta)$, then also $\left(p_{1}^{m}, S\right) \in \Lambda^{T}(\delta)$. Second, $S_{i} \pi_{1}\left(p_{1}^{m}\right)>S_{i} \pi_{1}(p)$ for all $i$ and for any vector $S$.

Moreover, no outcome $(p, S) \in \Lambda^{T}(\delta)$ such that $p<p_{1}^{m}$ and $\left(D_{2}\right)$ is slack can belong to $\Omega^{T}(\delta)$. This is because if, given $\delta,\left(D_{2}\right)$ is slack at $(p, S)$, then, by continuity, $\left(D_{2}\right)$ is also satisfied at $(p+\varepsilon, S)$ for sufficiently small $\varepsilon>0$. Moreover, if $\left(D_{1}\right)$ is satisfied at $(p, S)$, then, for any $\varepsilon \in\left(0, p_{1}^{m}-p\right],\left(D_{1}\right)$ is also satisfied at $(p+\varepsilon, S)$. However, $\pi_{1}^{\prime}(p)>0$ for all $p<p_{1}^{m}$, which implies that for any $\varepsilon \in\left(0, p_{1}^{m}-p\right], S_{i} \pi_{1}(p+\varepsilon)>S_{i} \pi_{1}(p)$ for all $i$.

Hence, if $(p, S) \in \Omega^{T}(\delta)$, then either $p=p_{1}^{m}$, or $p<p_{1}^{m}$ and $\left(D_{2}\right)$ is binding.

If $\delta \geq \widetilde{\delta}^{T}\left(p_{1}^{m}\right)$, then $\Lambda^{T}(\delta)$ contains some unconstrained Pareto-efficient outcomes. Obviously, if an unconstrained Pareto-efficient outcome is sustainable, i.e. if $(p, S) \in$ $\Lambda^{T}(\delta)$ and $p=p_{1}^{m}$, then $(p, S) \in \Omega^{T}(\delta)$.

For the remainder of this proof, consider any $(\widetilde{p}, \widetilde{S}) \in \Lambda^{T}(\delta)$ and any $\delta \in(0,1)$ such that

$$
c_{2}<\widetilde{p}<p_{1}^{m}
$$

and $\left(D_{2}\right)$ is binding:

$$
\widetilde{S}_{1}=1-(1-\delta) \frac{\pi_{2}(\widetilde{p})}{\pi_{1}(\widetilde{p})}
$$

Let us examine whether there exists any outcome in $\Lambda^{T}(\delta)$ that Pareto-dominates $(\widetilde{p}, \widetilde{S})$. At any alternative outcome with $p<\widetilde{p}$, at least one of the firms must be worse off, since the total prie $\pi_{1}(p)$ is smaller than $\pi_{1}(\widetilde{p}) .{ }^{31}$ Hence, to check whether $(\widetilde{p}, \widetilde{S})$ is a constrained Pareto-optimum or not, we only need to consider alternative outcomes with prices above $\widetilde{p}$.

This implies that if there are no outcomes with $p>\widetilde{p}$ in $\Lambda^{T}(\delta)$, that is, if $\delta=\widetilde{\delta}^{T}(\widetilde{p}),{ }^{32}$ then $(\widetilde{p}, \widetilde{S}) \in \Omega^{T}(\delta)$. This latter observation implies that whenever $\delta<\widetilde{\delta}^{T}\left(p_{1}^{m}\right)$, then $\left(p^{U}(\delta), S_{1}^{U}, 1-S_{1}^{U}\right) \in \Omega^{T}(\delta)$, where $p^{U}(\delta)$ denotes the highest sustainable price, uniquely defined by $\widetilde{\delta}^{T}\left(p^{U}(\delta)\right)=\delta$, and $S_{1}^{U}=1-(1-\delta) \frac{\pi_{2}\left(p^{U}(\delta)\right)}{\pi_{1}\left(p^{U}(\delta)\right)}$.

Therefore, let us focus on the case $\delta>\widetilde{\delta}^{T}(\widetilde{p})$ from now onwards, and consider only alternative outcomes with prices above $\widetilde{p}$. In fact, we can also restrict attention to alter-

\footnotetext{
${ }^{31}$ Obviously, firm 1 would also earn a lower payoff at any alternative outcome that has $p=\widetilde{p}$.

${ }^{32}$ Recall that if $c_{1}<c_{2}$, then $\widetilde{\delta}^{T}(p)$ is strictly increasing for all $p \in\left(c_{2}, \bar{p}\right)$.
} 
native outcomes with prices at most equal to $p_{1}^{m}$ : if, given $\delta$, there exists a sustainable outcome with a price strictly above $p_{1}^{m}$ that Pareto-dominates $(\widetilde{p}, \widetilde{S})$, then there also exists a sustainable outcome with price $p_{1}^{m}$ that Pareto-dominates $(\widetilde{p}, \widetilde{S})$.

It is easy to see that moving from $(\widetilde{p}, \widetilde{S})$ to an alternative outcome $\left(p^{\prime}, S^{\prime}\right) \in \Lambda^{T}(\delta)$ with $p^{\prime} \in\left(\widetilde{p}, p_{1}^{m}\right]$ always benefits firm 2: first, $\pi_{1}\left(p^{\prime}\right)>\pi_{1}(\widetilde{p})$, and second, $1-S_{1}^{\prime}>1-\widetilde{S}_{1}$, since firm 2's non-deviation constraint becomes more difficult to satisfy as $p$ increases (as is easy to check, $\frac{\pi_{2}(p)}{\pi_{1}(p)}$ is increasing in $p$ in the relevant range). The question is hence whether there exists an alternative outcome $\left(p^{\prime}, S^{\prime}\right) \in \Lambda^{T}(\delta)$ at which firm 1 earns higher profits than at $(\widetilde{p}, \widetilde{S}) \cdot(\widetilde{p}, \widetilde{S}) \in \Omega^{T}(\delta)$ if and only if the answer to this question is no.

For any $\delta$ and $p$ such that $\delta \geq \widetilde{\delta}^{T}(p)$, firm 1's equilibrium (per-period) payoff is maximal if $S_{1}$ is as large as possible, i.e. if $\left(D_{2}\right)$ is binding. Firm 1's maximal collusive payoff as a function of $p \in\left(c_{2}, p_{1}^{m}\right]$ given $\delta$ is thus equal to

$$
\bar{\Pi}_{1}(p ; \delta) \equiv \pi_{1}(p)-(1-\delta) \pi_{2}(p)
$$

The derivative of $\bar{\Pi}_{1}(p ; \delta)$ with respect to $p$ is

$$
\bar{\Pi}_{1}^{\prime}(p ; \delta)=\pi_{1}^{\prime}(p)-(1-\delta) \pi_{2}^{\prime}(p)
$$

Clearly:

$$
\frac{d \bar{\Pi}_{1}^{\prime}(p ; \delta)}{d \delta}=\pi_{2}^{\prime}(p)>0 .
$$

This implies that for every $p \in\left(c_{2}, p_{1}^{m}\right]$ there exists a unique $\widehat{\delta}(p) \equiv 1-\frac{\pi_{1}^{\prime}(p)}{\pi_{2}^{\prime}(p)}$ such that

$$
\bar{\Pi}_{1}^{\prime}(p ; \widehat{\delta}(p))=0
$$

$\bar{\Pi}_{1}^{\prime}(p ; \delta)<0$ if $\delta<\widehat{\delta}(p)$, and $\bar{\Pi}_{1}^{\prime}(p ; \delta)>0$ if $\delta>\widehat{\delta}(p)$. It is straightforward to check that

$$
\frac{\partial \widehat{\delta}(p)}{\partial p}>0 \Longleftrightarrow 2\left[D^{\prime}(p)\right]^{2}>D(p) D^{\prime \prime}(p) \text {. }
$$

Moreover, $\widehat{\delta}\left(p_{1}^{m}\right)=1$ and $\lim _{p \rightarrow c_{2}} \widehat{\delta}(p) \in(0,1)$.

Assuming that (25) holds, we can conclude the following. If $\delta>\lim _{p \rightarrow c_{2}} \widehat{\delta}(p)$, then there exists a unique $p^{L}(\delta) \in\left(c_{2}, p_{1}^{m}\right)$ such that $\bar{\Pi}_{1}^{\prime}(p ; \delta)>0$ if and only if $p<p^{L}(\delta)$. If $\delta \leq \lim _{p \rightarrow c_{2}} \widehat{\delta}(p)$ instead, then $\bar{\Pi}_{1}^{\prime}(p ; \delta)<0$ for all $p \in\left(c_{2}, p_{1}^{m}\right]$. In the latter case, let $p^{L}(\delta)=c_{2}$.

The implications of this are as follows:

If $\widetilde{p}<\min \left[p^{L}(\delta), p^{U}(\delta)\right]$, then the firms can achieve a Pareto-improvement within the set of sustainable outcomes: the outcome $\left(p^{\prime}, S^{\prime}\right)$ defined by $p^{\prime}=\min \left[p^{L}(\delta), p^{U}(\delta)\right]$ 
and $S_{1}^{\prime}=1-(1-\delta) \frac{\pi_{2}(p \prime)}{\pi_{1}(p \prime)}$ is sustainable and yields higher payoffs than $(\widetilde{p}, \widetilde{S})$ for both firms.

If $\widetilde{p} \geq p^{L}(\delta)$, on the other hand, then $(\widetilde{p}, \widetilde{S}) \in \Omega^{T}(\delta)$ : any outcome in $\Lambda^{T}(\delta)$ with a price above $\widetilde{p}$ yields lower profits than $(\widetilde{p}, \widetilde{S})$ for firm 1 , and as argued above, any outcome with a price below $\widetilde{p}$ must yield a lower payoff for at least one of the firms. Hence, no Pareto-improvement is achievable within $\Lambda^{T}(\delta)$. Q.E.D.

Proposition A1 Suppose that (stationary) collusion on some price $p^{*}>c_{2}$ and associated market shares $s^{*}$ can be supported by minmax punishments. Select any $p^{P} \in\left[0, c_{1}\right)$ and $T$ such that

$$
\left(1-\delta^{T}\right) \pi_{1}\left(p^{P}\right)+\delta^{T} s_{1}^{*} \pi_{1}\left(p^{*}\right)=0
$$

and let $\varepsilon \in\left[0, c_{1}-p^{P}\right]$.

Then the following punishment strategies minmax deviators and, together with the initial collusive path, form a subgame perfect equilibrium:

- Upon any deviation by firm 1, the sequence of prices and market shares starting from the first period after the deviation $t=1$ is as follows:

$$
\left[\left\{\left(p^{P}, p^{P}+\varepsilon, \ldots, p^{P}+\varepsilon\right),(1,0, \ldots, 0)\right\}_{t=1}^{T},\left\{\left(p^{*}, \ldots, p^{*}\right), s^{*}\right\}_{t=T+1}^{\infty}\right]
$$

- Upon any deviation by a firm $i \neq 1$, firms revert to the one-shot Bertrand equilibrium with market price $c_{2}$ from the first period after the deviation onwards.

Proof. First note that $s_{1}^{*}>0$, otherwise firm 1 could profitably deviate from stationary collusion on price $p^{*}>c_{2}$ and associated market shares $s^{*}$, even if the ensuing punishment is maximal for firm 1 . Since $c_{1}>0$, there then always exist $p^{P} \in\left[0, c_{1}\right)$ and $T$ such that (26) holds.

The proposed punishments minmax deviators by construction. First, by (26) firm 1's punishment leaves zero continuation profits to 1 . Second, any firm $i \neq 1$ earns zero profits in every period of $i$ 's punishment.

It remains to establish that the proposed strategy profile is indeed credible. For this we need to show that no firm has an incentive to deviate from any punishment at any stage and be punished in turn. As usual, it suffices to consider one-shot deviations. ${ }^{33}$

\footnotetext{
${ }^{33}$ By the one-shot deviation principle, "a strategy profile is subgame perfect if and only if there are no profitable one-shot deviations" (proposition 2.2.1 in Mailath and Samuelson (2006)).
} 
It is straightforward that no firm has an incentive to deviate from the punishment of any firm $i \neq 1$ : no firm can make a short-term gain by deviating from a static equilibrium, and a deviation starts a minmax punishment for the deviator.

To show that no firm has a strict incentive to deviate from 1's punishment, it is sufficient to consider deviations at $t=1$. Clearly, no firm has an incentive to deviate for $t>T$ if the proposed punishment strategies are indeed credible, since by assumption the collusive path can be supported by minmax punishments. Also, a firm has no incentive to deviate in any period $t \in[2, T]$ if it has no incentive to deviate at $t=1$ : The short-term gains from a deviation are the same at any stage $t \in[1, T]$, whereas the cost of foregoing the future switch to collusion increases with $t$.

Firm 1's best possible deviation from its own punishment at $t=1$ is to charge a price above $p^{P}+\varepsilon$ to earn zero instead of negative profits in the first period. This deviation would trigger the restart of firm 1's punishment with zero continuation profits. The firm is hence indifferent between complying and deviating optimally.

A firm $i \neq 1$ cannot benefit by deviating from 1's punishment at $t=1$ either: a deviation could not generate any short-term benefit but would nonetheless trigger a minmax punishment for firm $i$. Moreover, the assumption that the collusive path is sustainable by minmax punishments trivially implies that all firms earn non-negative profits in the carrot phase of firm 1's punishment. Hence, no firm $i \neq 1$ wants to deviate from 1's punishment:

$$
0+\delta \times 0=0 \leq 0+\delta^{T} s_{i} \pi_{i}\left(p^{*}\right)
$$

Proposition A2 If $\Lambda(\delta)=\varnothing$, i.e. if no stationary outcome with a market price strictly above $c_{2}$ can be supported in a subgame perfect equilibrium, then in any subgame perfect equilibrium firm 1's normalized discounted payoff lies in $\left[0, \pi_{1}\left(c_{2}\right)\right]$, and the sum of discounted payoffs of any firm $i \in\{2, \ldots, n\}$ is equal to 0 .

Proof. Let $B=\left\{i \in\{1, \ldots, n\} \mid c_{i} \leq c_{2}\right\}$, and denote by $\widehat{n} \in[2, n]$ the number of firms with marginal costs at most equal to $c_{2}$, that is, the number of elements of $B$. Then, as follows directly from the analysis in section $4.1, \Lambda(\delta)=\varnothing$ if and only if $\delta<\frac{\widehat{n}-1}{\widehat{n}}$.

Consider any path $\left\{P^{t}\right\}_{t=0}^{\infty}$. Let $p^{t} \equiv \min \left\{p_{i}^{t}\right\}_{i=1}^{n}$ and $\widetilde{p} \equiv \sup \left\{p^{t}\right\}_{t=0}^{\infty}$. Since $p_{i}^{t} \in(0, \bar{p})$ for all $i$ and all $t$, a finite $\widetilde{p}$ exists.

Suppose that $\delta<\frac{\widehat{n}-1}{\widehat{n}}$ and that $\widetilde{p}>c_{2}$. For the path $\left\{P^{t}\right\}_{t=0}^{\infty}$ to be supported as a subgame-perfect equilibrium outcome, with the associated sequence of market sharing 
rules $\left\{s^{t}(\cdot)\right\}_{t=0}^{\infty}$, it is necessary that the following non-deviation condition holds in every period $t$ and for every $i \in B$ :,

$$
\sum_{T=t}^{\infty} \delta^{T-t} s_{i}^{T}\left(P^{T}\right) \pi_{i}\left(p_{i}^{T}\right) \geq \pi_{i}\left(\min \left[p^{t}, p_{i}^{m}\right]\right) .
$$

As $s_{i}^{t}\left(P^{t}\right)=0$ if $p_{i}^{t} \neq p^{t},(27)$ implies that

$$
\sum_{T=t}^{\infty} \delta^{T-t} s_{i}^{T}\left(P^{T}\right) \pi_{i}\left(p^{T}\right) \geq \pi_{i}\left(\min \left[p^{t}, p_{i}^{m}\right]\right) .
$$

Since $\pi_{i}(p) \leq \pi_{i}\left(\min \left[p, p_{i}^{m}\right]\right)$ for any $t$, it follows from $(28)$ that

$$
\sum_{T=t}^{\infty} \delta^{T-t} s_{i}^{T}\left(P^{T}\right) \pi_{i}\left(\min \left[p^{T}, p_{i}^{m}\right]\right) \geq \pi_{i}\left(\min \left[p^{t}, p_{i}^{m}\right]\right)
$$

Moreover, since $\pi_{i}\left(\min \left[p, p_{i}^{m}\right]\right)$ is non-decreasing in $p$, we have $\pi_{i}\left(\min \left[p^{t}, p_{i}^{m}\right]\right) \leq \pi_{i}\left(\min \left[\widetilde{p}, p_{i}^{m}\right]\right)$ for all $i$ and all $t$. (29) hence implies that

$$
\sum_{T=t}^{\infty} \delta^{T-t} s_{i}^{T}\left(P^{T}\right) \pi_{i}\left(\min \left[\widetilde{p}, p_{i}^{m}\right]\right) \geq \pi_{i}\left(\min \left[p^{t}, p_{i}^{m}\right]\right) .
$$

From $\widetilde{p}>c_{2}$ it follows that $\pi_{i}\left(\min \left[\widetilde{p}, p_{i}^{m}\right]\right)>0$ for all $i \in B$. Therefore, (30) is equivalent to

$$
\sum_{T=t}^{\infty} \delta^{T-t} s_{i}^{T}\left(P^{T}\right) \geq \frac{\pi_{i}\left(\min \left[p^{t}, p_{i}^{m}\right]\right)}{\pi_{i}\left(\min \left[\widetilde{p}, p_{i}^{m}\right]\right)} .
$$

Summing over all $i \in B$ and noting that $\sum_{i \in B} s_{i}^{T}\left(P^{T}\right) \leq 1$ for all $T$ yields

$$
\frac{1}{1-\delta} \geq \sum_{i \in B} \frac{\pi_{i}\left(\min \left[p^{t}, p_{i}^{m}\right]\right)}{\pi_{i}\left(\min \left[\widetilde{p}, p_{i}^{m}\right]\right)}
$$

The right-hand side of (32) can be made arbitrarily close to $\widehat{n}$ by choosing $t$ appropriately. However, $\delta<\frac{\widehat{n}-1}{\widehat{n}}$ if and only if $\frac{1}{1-\delta}<\widehat{n}$. There must hence be contradiction of (32) for some $t$. We can conclude that if $\delta<\frac{\widehat{n}-1}{\widehat{n}}$, then no subgame perfect equilibrium has $p^{t}>c_{2}$ in any period $t$.

Thus, if $\Lambda(\delta)=\varnothing$, then on any subgame perfect equilibrium path $s_{i}^{t}\left(P^{t}\right) \pi_{i}\left(p_{i}^{t}\right) \leq$ $\max \left\{\pi_{i}\left(c_{2}\right), 0\right\}$ in every period $t$ and for all $i$. Firm 1 's normalized discounted equilibrium payoff therefore cannot exceed $\pi_{1}\left(c_{2}\right)$ and the normalized discounted payoff of any firm $i \in\{2, \ldots, n\}$ is as most 0 . Finally, no firm can be forced down to a normalized discounted payoff below the firm's minmax, which is 0 here, on any equilibrium path. 


\section{References}

[1] Abreu, D.: Extremal Equilibria of Oligopolistic Supergames. Journal of Economic Theory 39, 191-225 (1986)

[2] Abreu, D.: Towards a Theory of Discounted Repeated Games. Econometrica 56, 383-396 (1988)

[3] Athey, S. and Bagwell, K.: Optimal Collusion with Private Information. Rand Journal of Economics 32(3), 428-465 (2001)

[4] Athey, S. and Bagwell, K.: Collusion with Persistent Cost Shocks. Econometrica, forthcoming (2006)

[5] Bae, H.: A Price-Setting Supergame between Two Heterogeneous Firms. European Economic Review 31, 1159-1171 (1987)

[6] Bain, J. S.: Output quotas in imperfect cartels. Quarterly Journal of Economics 62, 617-622 (1948)

[7] Bernheim, B. D. and Whinston, M. D.: Multimarket Contact and Collusive Behaviour. Rand Journal of Economics 21(1), 1-26 (1990)

[8] Blume, A.: Bertrand without fudge. Economics Letters 78, 167-168 (2003)

[9] Collie, D. R.: Sustaining Collusion with Asymmetric Costs, Cardiff Business School working paper (2004)

[10] Compte, O., Jenny, F., Rey, P.: Capacity Constraints, Mergers and Collusion. European Economic Review 46, 1-29 (2002)

[11] Cramton, P. C. and Palfrey, T. R.: Cartel Enforcement with Uncertainty about Costs. International Economic Review 31, 17-47 (1990)

[12] Davidson, C. and Denerecke, R.: Excess Capacity and Collusion. International Economic Review 31(3), 521-541 (1990)

[13] Dechenaux, E. and Kovenock, D.: Endogenous Rationing, Price Dispersion, and Collusion in Capacity Constrained Supergames. Krannert Graduate School of Management, Purdue University, working paper no. 1164 (2003) 
[14] Deneckere, R.J. and Kovenock, D.: Capacity-constrained price competition when unit costs differ. CMSEMS discussion paper No. 861, Northwestern University, 1989

[15] Deneckere, R.J. and Kovenock, D.: Bertrand-Edgeworth duopoly with unit cost asymmetry. Economic Theory 8, 1-25 (1996)

[16] European Commission: Commission Fines Five Companies in Citric Acid Cartel. Press Release, December 5, 2001

[17] European Commission: Commission Fines Five Companies in Sodium Gluconate Cartel. Press Release, March 19, 2002

[18] Gilo, D., Spiegel, Y., Moshe, Y.: Partial Cross Ownership and Tacit Collusion. Mimeo, Tel Aviv University, (2004)

[19] Hammond, S. D.: Caught in the Act: Inside an International Cartel. Department of Justice (2005)

[20] Harrington, J. E. Jr.: The Determination of Price and Output Quotas in a Heterogeneous Cartel. International Economic Review 32(4), 767-792 (1991)

[21] Ivaldi, M., Rey, P., Seabright, P., Tirole, J.: The Economics of Tacit Collusion. IDEI Working Paper n. 186, Report for DG Competition, European Commission, (2003)

[22] Jehiel, P.: Product differentiation and price collusion. International Journal of Industrial Organization 10, 633-641 (1992)

[23] Kihlstrom, R. and Vives, X.: Collusion by Asymmetrically Informed Firms. Journal of Economics and Management Strategy 1, 371-396 (1992)

[24] Lambson, V. E.: Optimal Penal Codes in Price-setting Supergames with Capacity Constraints. Review of Economic Studies 54, 385-297 (1987)

[25] Lambson, V. E.: Some Results on Optimal Penal Codes in Asymmetric Bertrand Supergames. Journal of Economic Theory 62, 444-468 (1994)

[26] Lambson, V. E.: Optimal Penal Codes in Nearly Symmetric Bertrand Supergames with Capacity Constraints. Journal of Mathematical Economics 24(1), 1-22 (1995)

[27] Mailath, G. J., and Samuelson, L. S.: Repeated Games and Reputations: Long-Run Relationship. Oxford: Oxford University Press 2006 
[28] McAffee, R. P. and McMillan J.: Bidding Rings. American Economic Review 82(3), 579-599 (1992)

[29] Pesendorfer, M.: A Study of Collusion in First-Price Auctions. Review of Economic Studies 67(3), 281-411 (2000)

[30] Porter, R. H.: Detecting Collusion. Review of Industrial Organization 26, 147-167 (2005)

[31] Roberts, K.: Cartel Behaviour and Adverse Selection. Journal of Industrial Economics 33, 401-413 (1985)

[32] Rothschild, R.: Cartel Stability when Costs are Heterogeneous. International Journal of Industrial Organization 17, 717-734 (1999)

[33] Scherer, F. M.: Industrial Market Structure and Economic Performance. Boston: Houghton Mifflin Company 1980

[34] Schmalensee, R.: Competitive Advantage and Collusive Equilibria. International Journal of Industrial Organization 5, 351-368 (1987)

[35] Tirole, J.: The Theory of Industrial Organization. Cambridge: MIT Press 1988

[36] Vasconcelos, H.: Tacit Collusion, Cost Asymmetries, and Mergers. Rand Journal of Economics 36(1), 39-62 (2005) 